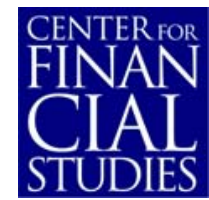

No. $2010 / 21$

\title{
Optimal Life Cycle Portfolio Choice with Housing Market Cycles
}

Marcel Marekwica and Michael Stamos 


\section{Center for Financial Studies}

The Center for Financial Studies is a nonprofit research organization, supported by an association of more than 120 banks, insurance companies, industrial corporations and public institutions. Established in 1968 and closely affiliated with the University of Frankfurt, it provides a strong link between the financial community and academia.

The CFS Working Paper Series presents the result of scientific research on selected topics in the field of money, banking and finance. The authors were either participants in the Center's Research Fellow Program or members of one of the Center's Research Projects.

If you would like to know more about the Center for Financial Studies, please let us know of your interest.

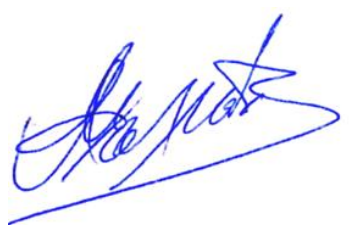

Prof. Michalis Haliassos, Ph.D.
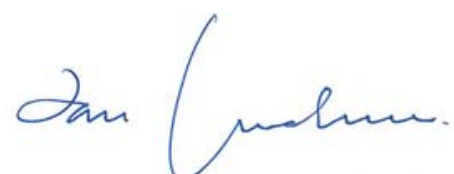

Prof. Dr. Jan Pieter Krahnen

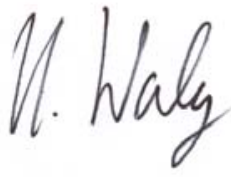

Prof. Dr. Uwe Walz 


\title{
Optimal Life Cycle Portfolio Choice with Housing Market Cycles*
}

\author{
Marcel Marekwica ${ }^{1}$ and Michael Stamos ${ }^{2}$
}

This Version: November 2010

\begin{abstract}
During the last decades households in the U.S. have experienced that residential house prices move in a persistent manner, i.e. that returns are positively serially correlated. Since an owner-occupied home is usually the largest investment of a household it is important to understand how households act when they base their consumption and investment decisions on this experience. We show in a setting with housing market cycles and households who can decide whether they rent or own the home, that - besides the consumption and the precautionary savings motive - serial correlation in house prices generates a new speculative motive for homeownership. In particular, we show how good and bad housing market cycles affect homeownership rates, leverage, stock investments and consumption and can explain empirically observed household behavior during housing market boom and bust periods.
\end{abstract}

JEL Classification: G11, D91

Keywords: Asset Allocation, Portfolio Choice, Housing Market Cycles, Real Estate

\footnotetext{
* We would like to thank Jamsheed Shorish and participants of the 2010 "Real Estate Finance and Economics" workshop at the University of Regensburg, and the 2010 D-CAF meeting for helpful comments and discussion. We gratefully acknowledge financial support from German Research Foundation. Opinions and errors are solely those of the authors and not of the institutions with whom the authors are affiliated.

1 Copenhagen Business School, Department of Finance, Tel: +45-3815-3628, Email: mma.fi@cbs.dk. 


\section{Introduction}

The recent housing market boom and bust has drastically visualized the importance of understanding how households account for housing market cycles when deciding upon homeownership, home size, leverage, stock investment, and consumption. Our paper contributes to the literature by setting up a realistically calibrated life cycle model which accounts for housing market cycles. That is, our model takes into account that returns in housing markets are serially correlated and hence that housing returns can be persistently above and below their long-term average. Even though the effect of serial correlation in stock market returns has been analyzed extensively in the literature 1 little is known about the effect of housing market cycles on portfolio decisions. This is surprising in the light of the results of the following analysis. A simple OLS regression of annual inflation-adjusted house index returns $r_{\text {house }}$ (Case-Shiller Index) and inflation-adjusted stock market returns $r_{\text {stock }}$ (S\&P 500 Index) on their lagged values using data from 1954 to 2009 gives

$$
\begin{gathered}
r_{\text {house }, t}=\underset{(-1.3757)}{-0.0029}+\underset{(18.9234)}{0.8626} \cdot r_{\text {house }, t-1}+\epsilon_{\text {house }, t} \\
r_{\text {stock }, t}=\underset{(2.4776)}{0.0241}+\underset{(1.2306)}{0.0754} \cdot r_{\text {stock }, t-1}+\epsilon_{\text {stock }, t}
\end{gathered}
$$

where t-values are in parentheses and the $R^{2}$ s are 0.5330 and 0.0048 , respectively. The autoregression parameters of 0.8626 in the regression with house index returns and of 0.0754 in case of stock market returns shows that the empirical evidence for cycles in housing markets is much more pronounced than the evidence in stock markets. Not to mention the statistical significance of results which is manifested in a much higher t-value for the slope and the substantially higher $R^{2}$. Thus, as first documented empirically in Case and Shiller (1989), housing prices are subject to market cycles. However, there is only limited research available how housing market cycles

\footnotetext{
${ }^{1}$ The literature on asset allocation decisions given predictability in stock market returns is vast compared to their statistical significance. Given the low statistical significance, there is an intense debate on whether the serial correlation is just spurious (Lanne (2002)) while the large string of portfolio choice literature assumes it is given and developed a sizable number of advanced portfolio choice models to account for it. It is known, that predictability can have a substantial effect on asset allocation (Kandel and Stambaugh (1996)). In settings with only one risky asset, Campbell (1987) and Fama and French (1989) find one-month t-bill rates and dividend yields to forecast stock returns. Brennan et al. (1997) find mean reversion in expected returns, Ang and Bekaert (2007) find dividend dividend yields and the short rate to predict excess returns at short horizons. Campbell and Viceira (1999) find expected excess log returns on risky stocks to follow an AR(1) process. The results of Pesaran and Timmermann (1995) suggest that in volatile markets returns can be better predicted than in calm markets. According to Campbell and Thompson (2008) out-of-sample predictability based on regressions can be improved by imposing sign restrictions in accordance with economic theory. The effect of predictability in the presence of multiple risky assets is e.g. analyzed in Fluck et al. (1997), Schroder and Skiadas (1999), Lynch (2001), Campbell et al. (2003), Schroder and Skiadas (2003), and Liu (2007). The work of Barberis (2000) represents a compromise in the debate since it takes into account the statistical insignificance by applying Bayesian statistics. It shows that the economic significance of stock return predictability can be substantial in portfolio decisions.
} 
affect optimal housing, consumption, and portfolio decisions $2^{2}$ In light of our simple regression study it seems to be obvious that household decisions can be substantially influenced when they are based on the statistically valid assumption that housing markets exhibit cycles. Also the empirical evidence of homeownership rates and leverage of U.S. households suggests that it may be a valid assumption that households base their decisions on their experience of persistently rising house prices and try to profit from what they have learned during their life-time. According to data from the U.S. census bureau the homeownership rate increased from $67.5 \%$ in 2001 to $68.4 \%$ in 2007 and, more striking during the same period, the average leverage of home owners increased from 1.56 to 1.82 according to the Survey of Consumer Finances (SCF). It is also noteworthy that during the same period the average exposure to equity decreased from $21.6 \%$ to $18.0 \%$ according to the SCF and the ratio of real private consumption (Datastream code USOCFPCN) to real disposable income (Datastream code USOCFDI) increased from $93.5 \%$ to $94.5 \%$.

The recent subprime crisis has drastically shown the importance of housing investments since the effect of continuously rising and afterwards falling house prices on household decisions was massive. When house prices started falling, massive deleveraging took place as well as a significant reduction of household consumption spending ${ }^{3}$ The ratio of real private consumption to real disposable income in the U.S. dropped from $94.5 \%$ in 2007 to $92.4 \%$ in 2009 whereas the homeownership rate decreased from $68.4 \%$ to $67.2 \%$.

In our study we acknowledge the fact that homeownership differs from an investment in conventional assets like, for instance, stocks or bonds. Owner-occupied homes are at the same time both consumption and investment goods. Households both derive utility from living in a nice home and are at the same time exposed to price changes in their homes. We follow the usual way to model the utility derived from the housing investment, by using utility functions of the Cobb-Douglas type 4 Flavin and Yamashita (2002) show that rental markets allow to split the utility derived from a private home into a consumption and an investment part. Yamashita (2003) provides empirical verification for this finding. Case et al. (2005) and Campbell and Cocco (2007) show empirically that housing investments also affect households' consumption

\footnotetext{
Corradin et al. (2010) generalize earlier work of Damgaard et al. (2003) to a setting with housing market cycles. However, in their model they neither include non-financial labor income nor do they endogenize the decision of whether to own or rent a home.

${ }^{3}$ The results in Amromin et al. (2010) suggest that innovative mortgages like interest only or teaser mortgages might also have contributed to the recent boom and bust in the real estate market.

${ }^{4}$ See e.g. Damgaard et al. (2003), Cocco (2005), Yao and Zhang (2005), Li and Yao (2007), Yao and Zhang (2008), Van Hemert (2010) or Kraft and Munk (2010).
} 
levels.

Trading in owner-occupied homes is subject to substantially higher transaction costs than trading in conventional assets. To avoid these transaction costs, home owners should have a strong locational preference for working in their region. The impact of transaction costs has first been analyzed by Grossman and Laroque (1990) for illiquid durable consumption goods. Cauley et al. (2007) transfer their work to the housing context. Transaction costs used are around $6 \%$ (Yao and Zhang (2005) for selling) or $8 \%$ (Cocco (2005) for sales and repurchasing). The key results from the transaction costs literature for conventional assets also apply for housing investments. In particular, the transaction costs cause a no-trade region in which the advantage from changing the portfolio position is outweighed by the transaction costs associated with some such trade $5^{5}$ In our model it is therefore vital to test whether the serial correlation in house prices can be exploited by changing the homeownership status and/or the home size after accounting for transaction costs.

Our model predicts that not only the consumption, the buffer-stock saving and the precautionary savings motive influence household decisions but also a speculation motive. Thus, our model shows that not only age, labor income and wealth are determinants for household decisions but also the current state of the housing market. This result is driven by the statistical significance of serial correlation as well as the size of the housing investment. Our model proposes optimal household decisions which are commensurate to empirical household behavior.

We assume that households are dynamic expected life-time utility maximizer who account for a risky house price process with mean-reverting drift term, risky labor income, and risky stock markets to decide upon owning or renting a home, the home size, the investment ratios, as well as consumption of a non-durable good. We calibrate the house price process in the way that the drift term is an affine function of the past annual house price return. Hence if the house price return is above (below) average it is likely that the next year return will be above (below) average too, hence this defines a good (bad) housing market cycle, respectively. Given the regression above it is no surprise that the estimated parameters are highly significant. Our model predicts that the half-life of housing market cycles is roughly 4.5 years. This indicates that cycles are long enough to react and change the homeownership status or the home size even if moving cost are $8 \%$ for owners and $1 \%$ for renters.

${ }^{5}$ See e.g. Constantinides (1986), Davis and Norman (1990), Balduzzi and Lynch (1999), Lynch and Balduzzi (2000), Leland (2001), Muthuraman and Kulmar (2006) and Lynch and Tan|(2009). 
In good cycles our model predicts increases in homeownership rate, home size, and leverage. In order to finance the home and to profit from the high expected house price appreciation, the household reduces instantaneously consumption rates and the proportion of stocks, implying a substitution effect in terms of favoring housing consumption over non-durable good consumption, and housing investment over stock market investment. In the long-run, however, the wealth effect dominates the substitution effect since the household accumulates in expectation a sizable amount of wealth due to the leveraged housing investment so that the absolute levels of consumption as well as stock market investments are increasing. Even when the expected house appreciation is not pronounced enough to increase the size of an owned home, the model predicts that households increase consumption rates and stock investments due to the expected wealth increase.

In bad states of the housing market cycle, such as the current housing market crisis, our model predicts decreasing homeownership rates, housing investments, and leverage ratios. While instantaneously consumption ratios and stock ratios are increasing due to the substitution effect, the wealth effect leads to a reduction of consumption levels and stock market investments within short time. Simulations show that given the persistence of house price returns and the procyclical behavior of households, it is likely that it takes years to recover from a housing market crisis. It is noteworthy that the household only sells a home if the expected house price slump is significant. The reason is that for mild slumps transaction costs outweigh the benefits of selling the home so that the household optimally decides to keep the home and to persevere the housing bust until it is over.

Our welfare analysis shows that the welfare losses of both erroneously assuming serial correlation when house price returns are i.i.d. and assuming i.i.d. returns when house price returns are serially correlated, are seizable and heavily driven by the risk of losses in leveraged housing investments. This risk is especially pronounced for younger investors that are endowed with lower levels of financial wealth. Welfare losses from ignoring existing cycles tend to outweigh welfare costs from erroneously assuming non-existing cycles.

Further, our model predicts homeownership rates which come close to empirical patterns in the U.S. while earlier studies like Yao and Zhang (2005) predicted rates of $100 \%$ for large parts of the household's life cycle. In our base-case parameter setting, the homeownership rate is around $80 \%$. When we account for higher correlation between house price and labor income risk the homeownership rate is at around $70 \%$ which comes very close to the homeownership 
rate of $67.2 \%$ reported by the U.S. Census Bureau for 2009 .

This paper proceeds as follows. In Section 2 , we introduce our model and the household's optimization problem. In Section 3, we discuss the effect of housing market cycles on life cycle consumption, housing, and portfolio decisions by presenting numerical results and performing an impulse-response Monte Carlo analysis that highlights the long-run effects of housing market booms and busts on housing, consumption and investment decisions. The section also provides a welfare analysis in order to test the economic as opposed to the statistical significance of housing market cycles. Section 4 checks the robustness of our results and is followed by a conclusion in Section 5

\section{The Household Decision Problem with Housing Market Cycles}

\subsection{Preferences}

We employ a continuous time model, where $t$ determines the household's adult age (computed as actual age minus 20) and $T$ denotes the end of the household's life cycle. Household's utility at each point in time is characterized through a Cobb-Douglas utility function $u$ defined over consumption and housing:

$$
u(C, Q)=\frac{\left(C^{1-\psi} Q^{\psi}\right)^{1-\gamma}}{1-\gamma}
$$

where, $C$ is the amount the household consumes of a non-durable good, $Q$ is the size of the home the household lives in, $\gamma$ is the coefficient of relative risk aversion and $\psi$ is the relative preference over housing consumption. The household's time-separable additive utility function $U$ is given by

$$
U=\int_{0}^{T} \delta^{-t} u\left(C_{t}, Q_{t}\right) d t
$$

with $\delta$ determining the subjective discount rate. The household's lifespan is modeled from age $20(t=0)$ to $80(t=T=60)$ and retirement begins at age $65\left(t_{\text {retire }}=45\right)$. As a result, the working life is 45 years long while the length of the retirement phase is 15 years. Preference parameters are set to values standard in the life cycle literature, including a coefficient of relative risk aversion of $\gamma=10$ as in Cocco et al. 2005) and a utility discount factor of $1 / \delta=0.96$. The housing preference is set to $\psi=0.2$ as in Yao and Zhang (2005) and consistent with the average proportion of household housing expenditure in the 2001 Consumer Expenditure Survey. 


\subsection{Housing Markets}

The household's investment opportunity is comprised of a housing, a stock, and a bond market. The housing and the stock market are assumed to be risky while the bond market is risk-free. House price and stock market risk can be correlated, reflecting that both tend to depend on a common risk factor, like for instance the macroeconomic state of the economy.

The price of one housing unit $Q=1$ is assumed to evolve according to

$$
\begin{gathered}
d H / H=\left(r+\bar{\lambda}_{H}+\lambda_{H, t}\right) d t+\sigma_{H} d Z_{H}, \\
\lambda_{H, t}=\beta\left(\xi_{t}-\bar{\xi}\right)
\end{gathered}
$$

where $\bar{\lambda}_{H}$ denotes the long-term average risk premium and $\lambda_{H, t}$ denotes the cyclical risk premium. The cyclical risk premium is by definition time-varying with mean zero. The time-varying cyclical risk premium allows us to model cycles exhibiting above average and below average house price returns. Therefore, $\beta>0$ determines the sensitivity to the difference of a predictive signal $\xi_{t}$ minus its long term average $\bar{\xi}$. $\sigma_{H}$ is the instantaneous volatility of house price changes, and $d Z_{H}$ is the increment of a Brownian motion.

In what follows, we employ the Ornstein-Uhlenbeck process to model the predictive signal dynamics since we aim to model stationary cycles:

$$
d \xi=\kappa(\bar{\xi}-\xi) d t+\sigma_{\xi} d Z_{\xi}
$$

where $\kappa>0$ determines the speed of mean reversion, $\bar{\xi}$ is the long-run expected signal $\lim _{t \rightarrow \infty} E\left(\xi_{t}\right)$, and $\sigma_{\xi}$ is the instantaneous volatility of the expected risk premium. The expected future signal is $E\left(\xi_{t+\Delta t} \mid \xi_{t}\right)=\bar{\xi}+\left(\xi_{t}-\bar{\xi}\right) e^{-\kappa \Delta t}$, its variance is $\operatorname{Var}\left(\xi_{t+\Delta t}\right)=\frac{\sigma_{\xi}^{2}}{2 \kappa}\left(1-e^{-2 \kappa \Delta t}\right)$. If the current signal realization is above the long-term average $\left(\xi_{t}>\bar{\xi}\right)$ the expected future signal is also above average $\left(E\left(\xi_{t+\Delta t} \mid \xi\right)>\bar{\xi}\right)$ since $e^{-\kappa \Delta t}>0$, and vice versa. The correlation between the predictive signal shocks and the house price shocks is defined by $d Z_{\xi} d Z_{H}=\rho_{H \xi} d t$. 
The expected log-return and variance of house prices are given by

$$
\begin{aligned}
\mathrm{E}\left[\ln \left(H_{t+\Delta t} / H_{t}\right)\right]= & \left(r+\bar{\lambda}_{H}-1 / 2 \sigma_{H}^{2}+\lambda_{H, t}\right) \Delta t / \kappa\left(1-e^{-\kappa \Delta t}\right) \\
\operatorname{Var}\left[\ln \left(H_{t+\Delta t} / H_{t}\right)\right]= & \left(\sigma_{H}^{2}+\frac{\beta^{2} \sigma_{\xi}^{2}}{\kappa^{2}}+2 \frac{\beta \rho_{H \xi} \sigma_{H} \sigma_{\xi}}{\kappa}\right) \Delta t \\
& -2\left(\frac{\beta^{2} \sigma_{\xi}^{2}}{\kappa^{3}}+\frac{\beta \rho_{H \xi} \sigma_{H} \sigma_{\xi}}{\kappa^{2}}\right)\left(1-e^{-\kappa \Delta t}\right)+\frac{\beta^{2} \sigma_{\xi}^{2}}{2 \kappa^{3}}\left(1-e^{-2 \kappa \Delta t}\right) .
\end{aligned}
$$

The current level of the predictive signal $\xi_{t}$ is a state variable which influences utility from taking house price risk by investing in house equity as opposed to investing in stocks or bonds. Further, it determines the motivation to defer consumption because consuming now by renting a big home or by consuming the non-durable good is costly if the housing market is in a relatively good state $\lambda_{H, t}>0$.

To estimate the house price process we use annual real U.S. home price from 1953 to 2009 $(N=56$ years). Figure 1 shows the evolution of U.S. home and stock prices based on data from Robert Shiller's website 6

Please insert Figure 1 about here.

The nominal home price time series is constructed of PHCPI data from from 1953 to 1974, OFHEO data from 1975 to 1986, and the S\&P/Case-Shiller home price index from 1987 to 2009. The house prices are deflated using the U.S. CPI data provided by Bureau of Labor Statistics. Especially the lower graph, depicting the evolution of the house price index, highlights the high level of serial correlation.

To estimate the signal process, we assume that the predictive signal is given by the real annual house index return of the preceding year. The intuition is that if the preceding return in $t-1$ is above (below) the average $\bar{\xi}$ return, the cyclical housing risk premium $\lambda_{H, t}$ is positive, indicating a good state of the housing market (negative, indicating a bad cycle of the housing market). Regressing annual real log-housing returns on preceding real log-housing returns allows us to estimate the required parameters and their standard errors. Our results are summarized in Table 1

Please insert Table 1 about here.

The empirical long-term housing risk premium is $\bar{\lambda}_{H}=-1.68 \%$ and the house price index volatility is $\sigma_{H}=3.74 \%$. Price changes of individual homes are far from perfectly correlated, 6ttp://www.econ.yale.edu/ ${ }^{\text {shiller/. }}$ 
the aggregation in the house price index therefore reduces house price volatility. Case and Shiller (1989) argue that the volatility of individual house prices is close to $15 \%$. We follow this estimate and set $\sigma_{H}=13.32 \%$, which, together with the volatility of the house price signal implies a volatility of the log-house prices of $15 \%$ as in Van Hemert (2010). The estimated autoregressive coefficient is $\beta=0.8567$, indicating a strong dependence to the past annual return. Since the standard error of $\beta$ is 0.1034 the serial dependency is statistically significant.

The unconditional average log-return is $\bar{\xi}=0.22 \%$ and the volatility of the predictive signal is $\sigma_{\xi}=4.054 \%$. The estimated mean reversion speed is $\kappa=0.1478$. This parameter determines the degree of persistence of housing market cycles. The difference $\xi_{t}-\bar{\xi}$ is in expectation reduced by the factor $e^{-\kappa \Delta t}<1$ from $t$ to $t+\Delta t$. Hence the expected half-life $t_{h a l f}$ of the difference is derived from $e^{-\kappa t_{\text {half }}}=0.5 \Leftrightarrow t_{\text {half }}=-\ln 0.5 / \kappa$. Hence, $\kappa=0.1478$ indicates that the half-life of housing market cycles is $t_{\text {half }}=4.7$ years. The higher $\kappa$, the shorter are housing market cycles in expectation. The half-life of housing market cycles determines whether households can benefit from anticipating future house price returns, especially due to the presence of substantial transaction costs. Since a shorter half-life will reduce the benefits of predictability, we check in a robustness analysis how an increase of $\kappa$ by one standard deviation changes our results.

The value of a home with a certain size $Q$ is $Q \cdot H$. Households can rent or own the house they live in. Renters pay continuously renting costs $m^{\text {rent }} Q H d t$ with $m^{\text {rent }}$ denoting the rate of renting costs. Owners pay maintenance costs $m^{\text {own }} Q H d t$ where $m^{\text {own }}$ is the rate of maintenance costs. If the owner is not maintaining the home, the maintenance expenses can be interpreted as depreciation costs. Finally, the rate of running housing costs $m$ can be expressed as

$$
m\left(I_{\text {own }}\right)=m^{\text {rent }}\left(1-I_{\text {own }}\right)+m^{\text {own }} I^{\text {own }},
$$

where $I^{\text {own }}=1$ if the household owns the home and $I^{\text {own }}=0$ if the household rents the home.

Non-recurring housing expenses $\tau$ are realized if the household changes the ownership status $I_{t+}^{\text {own }} \neq I_{t}^{\text {own }}$ where $t+$ denotes one logical moment after $t$. If the household becomes a new owner (renter) transaction costs are $\tau_{\text {own }} \cdot Q_{t+} \cdot H_{t}$ or $\tau_{\text {rent }} \cdot Q_{t+} \cdot H_{t}$ where $\tau_{\text {own }}\left(\tau_{\text {rent }}\right)$ denotes the percentage cost of becoming an owner (renter) and $Q_{t+}$ is the size of the new home. Transaction costs are also incurred if the household remains a renter $I_{t+}^{\text {own }}=I_{t}^{\text {own }}=0$ or owner $I_{t+}^{\text {own }}=$ $I_{t}^{\text {own }}=1$ in case she changes the home size, i.e. $Q_{t+} \neq Q_{t}$. Transaction costs can be summarized 
as follows

$\tau\left(Q_{t+}, I_{t+}^{\text {own }}, I_{t}^{\text {own }}\right)=Q_{t+} H_{t} \begin{cases}\tau_{\text {own }} & , \text { if new owner }\left(\left(I_{t+}^{\text {own }}-I_{t}^{\text {own }}\right)=1\right) \\ \tau_{\text {rent }} & , \text { if new renter }\left(\left(I_{t+}^{\text {own }}-I_{t}^{\text {own }}\right)=-1\right) \\ \tau_{\text {own }} & , \text { if owner changes home size }\left(I_{t+}^{\text {own }}=I_{t}^{\text {own }}=1, Q_{t+} \neq Q_{t}\right) \\ \tau_{\text {rent }} & , \text { if renter changes home size }\left(I_{t+}^{\text {own }}=I_{t}^{\text {own }}=0, Q_{t+} \neq Q_{t}\right) \\ 0 \quad & , \text { if household stays in home }\left(I_{t+}^{\text {own }}=I_{t}^{\text {own }}, Q_{t+}=Q_{t}\right) .\end{cases}$

We set the minimum equity requirement for a home purchase to $E^{\min }=20 \%$ as in Yao and Zhang (2005) and Van Hemert (2010). The renting costs rate and the maintenance costs rates are set to $m^{\text {rent }}=7 \%$ and $m^{\text {own }}=1.5 \%$, respectively. Moving costs for households moving to an owner-occupied or a rented home are set to $\nu_{\text {own }}=8.0 \%$ and $\nu_{\text {rent }}=1.0 \%$ as in Cocco (2005) and Van Hemert (2010), respectively.

\subsection{Capital Markets}

The representative stock market index is assumed to follow the geometric Brownian motion

$$
d S / S=\left(r+\lambda_{S}\right) d t+\sigma_{S} d Z_{S}
$$

where $r$ denotes the risk-free interest rate, $\lambda_{S}$ represents the long-run expected risk premium, $\sigma_{S}$ the instantaneous volatility of stock price changes, and $d Z_{S}$ is the increment of a Brownian motion. Bond prices evolve according to

$$
d B / B=r d t !^{7}
$$

The equity risk premium is set to $\lambda_{S}=4 \%$ and volatility at $\sigma_{S}=16 \%$. These values are in line with recent studies including e.g. Claus and Thomas (2001), Cocco et al. (2005) or Gomes and Michaelides (2005) and acknowledge the view that future expected stock returns should be below its historical average. We set correlations between stock returns and house price risk as well as house price risk and the signal to their empirical estimates of $\rho_{S H}=0.22$ and $\rho_{H \xi}=0.9967$, respectively. The correlation between stocks returns and the predictive signal

\footnotetext{
${ }^{7}$ In order to keep the model parsimonious we assume that the interest rate of the bond as well as for the mortgage is the same.
} 
shocks is set to $\rho_{S \xi}$ to 0.22 . The risk-free interest rate is set to $r=\ln (1+2 \%)$.

\subsection{Labor Income}

Several studies have recently highlighted the importance of including labor income as a nontradable asset in portfolio choice frameworks (e.g. Bodie et al. (1992), Viceira (2001), or Cocco et al. (2005)). The drop in labor income at retirement creates a precautionary savings motive. Further, labor income risk is shown to create demand for buffer stock saving early in life. Since labor income is a regular stream of positive cash flows it can be viewed as a coupon bearing bond with stochastic coupon payments. Hence, households with labor income will hold a high proportion of stock investments when they are young and shift stocks to bonds while they get older and their human capital shrinks to 0 .

Further, the riskiness of labor income is an important factor when a household decides about buying or renting a home because the household might be forced to sell its home due to falling labor income. Including stochastic income into our analysis is also important to understand the drawbacks of the inflexibility created by homeownership due to transaction costs. We assume that the household earns unspanned labor income $L$ which is subject to permanent shocks during worklife and constant afterwards. So we have

$$
d L / L= \begin{cases}g(t) d t+\sigma_{L} d Z_{L} & , \text { during worklife } t<t_{\text {retire }} \\ -\left(1-R_{\text {retire }}\right) & , \text { entering retirement } t=t_{\text {retire }} \\ 0 & , \text { during retirement } t>t_{\text {retire }}\end{cases}
$$

where $t_{\text {retire }}$ is the age the household enters her retirement phase, and $g(t)=b+2 c(t+20)+$ $3 d(t+20)^{2}$ is the age-dependent expected real income growth rate as in Van Hemert (2010). $\sigma_{L}$ reflects the level of income risk, and $d Z_{L}$ is the increment of a Brownian motion. $R_{\text {retire }}$ is the replacement ratio which is defined as first pension income divided by last labor income. We set the correlation between stocks and labor income to $\rho_{S L}=0.2$ as in Cocco (2005), reflecting the generally low correlation between the stock and the labor market, which essentially makes labor income risk unspanned risk. Correlation between house price and labor income shocks is set to $\rho_{H L}=0.2$ as in Yao and Zhang 2005). The correlation between labor income and the predictive signal is also set to $\rho_{\xi L}=0.2$.

Parameter values of labor and pension income processes are set in accordance with Cocco 
et al. (2005); our base case sets the parameters of the deterministic labor income drift $g(t)$ and volatility parameters for permanent labor income shocks during working life to represent U.S. households with high school education $\left(b=0.1682, c=-0.00323, d=0.00002, \sigma_{L}=0.1\right)$ as in Van Hemert (2010). The labor income profile exhibits a hump-shape with expected rising income until age 45 and declining income thereafter. When entering retirement, households receive a constant pension income amounting to $R_{\text {retire }}=70 \%$ of the last realized labor income, that is to account for social security benefits. We summarize our choice of base case parameters in Table 2 ,

Please insert Table 2 about here.

\subsection{The Household's Optimization Problem}

The household maximizes expected lifetime utility by deciding at each point in time $t \in[0, T]$ upon consumption of the non-durable good $C$, the home size $Q$, the ownership status $I^{\text {own }}$, the stock fraction $w^{s}$, and the bond fraction $\pi^{b}$. Hence, the indirect value function $V$ is given by

$$
\begin{gathered}
V(q, i, \xi, l, w, h, t)=\sup _{\left\{C_{s}, Q_{s}, I_{s}^{o w n}, \pi_{s}^{s}, \pi_{s}^{b}\right\}_{s=t}^{T}} \mathbb{E}\left[\int_{t}^{T} \delta^{s-t} u\left(C_{s}, Q_{s}\right) d s \mid\right. \\
\left.Q_{t}=q, I_{t}^{\text {own }}=i, \xi_{t}=\xi, L_{t}=l, W_{t}=w, H_{t}=h\right],
\end{gathered}
$$

where $W$ denotes the households total wealth, $\pi^{s}$ and $\pi^{b}$ are the fractions of total wealth held in stocks and bonds, respectively. The indirect utility function is given by

$$
\begin{gathered}
V(q, i, \xi, l, w, h, t)=\sup _{\left\{C_{t}, Q_{t}, I_{t}^{\text {own }}, \pi_{t}^{s}, \pi_{t}^{b}\right\}} u\left(C_{t}, Q_{t}\right) \Delta t \\
+\delta^{-\Delta t} \mathbb{E}\left[V\left(Q_{t+\Delta t}, I_{t+\Delta t}^{\text {own }}, \xi_{t+\Delta t}, L_{t+\Delta t}, W_{t+\Delta t}, H_{t+\Delta t}, t+\Delta t\right)\right. \\
\left.Q_{t}=q, I_{t}^{\text {own }}=i, \xi_{t}=\xi, L_{t}=l, W_{t}=w, H_{t}=h\right] .
\end{gathered}
$$

The household's total wealth $W$ is

$$
W=W^{F}+W^{H},
$$

where $W^{H}=I^{\text {own }} Q H$ denotes the housing wealth and $W^{F}=W\left(\pi^{s}+\pi^{b}\right)$ is the household's financial wealth with $\pi^{s}$ and $\pi^{b}$ reflecting the proportions of total wealth held in stocks and bonds, respectively. 
The household's intertemporal budget restriction is given by

$$
\begin{aligned}
d W^{F}= & \pi^{s} W \frac{d S}{S}+\pi^{b} W \frac{d B}{B}+(L-C) d t \\
& -\tau\left(Q_{t+}, I_{t+}^{\text {own }}, I_{t}^{\text {own }}\right) \\
& -m\left(I^{\text {own }}\right) H Q d t \\
& -H \cdot\left(I_{t+}^{\text {own }} Q_{t+}-I_{t}^{\text {own }} Q_{t}\right) .
\end{aligned}
$$

Further, we impose the restriction that the household cannot short stocks $\left(\pi^{s} \geq 0\right)$ while bonds can only be shorted in order to finance the ownership of a home. The minimum equity requirement when owning a home is given by $E^{\text {min }}>0$ so that the amount of debt $-\pi^{b} W$ has to obey

$$
-\pi^{b} W \leq\left(1-E^{\text {min }}\right) I^{\text {own }} H Q
$$

The state space of the optimization problem is reduced by two dimensions by exploiting the homogeneity of the time-separable Cobb- Douglas utility function in $C$ and $Q$ so that the following equivalent optimization problem holds

$$
\begin{gathered}
\left(\frac{W_{t}}{H_{t}^{\psi}}\right)^{1-\gamma} \Phi\left(\frac{H_{t} Q_{t}}{W_{t}}, I_{t}, \xi_{t}, \frac{L_{t}}{W_{t}}, t\right)=\sup _{\left\{c_{t}, q_{t}, I_{t}, \pi_{t}^{s}, \pi_{t}^{b}\right\}} u\left(c_{t}, q_{t}\right) \Delta t \\
+\delta^{-\Delta t_{\mathbb{E}}}\left[\left(\frac{W_{t+\Delta t}}{H_{t+\Delta t}^{\psi}}\right)^{1-\gamma} \Phi\left(\frac{H_{t+\Delta t} Q_{t+\Delta t}}{W_{t+\Delta t}}, I_{t+\Delta t}, \xi_{t+\Delta t}, \frac{L_{t+\Delta t}}{W_{t+\Delta t}}, t+\Delta t\right)\right],
\end{gathered}
$$

where $c_{t}=C_{t} / W_{t}$ is the consumption rate and $q_{t}=Q_{t} / W_{t}$ is the household's normalized home size where we have normalized $H_{t}$ to 1.8 So, the policy functions $c, q, I, \pi^{s}, \pi^{b}$ and the value function $\Phi$ depend on five state variables: 1) the normalized size of the home $w_{H}=\frac{H Q}{W}$, the household lives in, 2) the ownership status $I, 3)$ the predictive signal $\xi, 4)$ the labor incomewealth ratio $l_{w}=\frac{L}{W}$, and 5) time $t$.

\footnotetext{
${ }^{8}$ Due to this normalization, the terms normalized home size and house value can be used interchangeably.
} 


\section{Optimal Household Decisions in the Presence of housing mar- ket Cycles}

\subsection{Optimal policy functions}

We compute the optimal policy functions consumption rate $c($.$) , normalized home size q($.$) ,$ homeownership status $I($.$) , stock fraction \pi^{s}($.$) , bond fraction \pi^{b}($.$) numerically by backward in-$ duction in the discretized five-dimensional state-space. We discretize continuous state-variables: normalized value of the home $w_{H}=\frac{H Q}{W}$, the housing market signal $\xi$, the labor income-wealth ratio $l_{w}=\frac{L}{W}$, and time $t$. The time-step is one year. The only discrete state variable is the homeownership status $s$ (we set $s=1$ for owners and $s=0$ for renters).

In what follows, we discuss the numerically computed optimal policies and show how housing market cycles affect not only rational housing decisions but also consumption behavior as well as investments in stocks and bonds. The graphs in Figure 2 show the optimal policy functions for households aged 35 who have been renting their home previously and are endowed with a labor income-wealth ratio of $l_{w}=0.239$

The consumption rate $c$ and the normalized home size $q$ as well as the equity and bond exposure are reported in relation to the household's wealth level before trading, i.e. before deducting potential transaction costs.

In order to show how household behavior is affected by the housing market cycle, we show the optimal policy as a function of the cyclical housing risk premium $\lambda_{H, t}$ and the normalized home size before trading $w_{H}$.

Please insert Figure 2 about here.

The surfaces with thick (thin) lines indicate the states in which the household decides to rent (own) the home, respectively. The upper left graph of Figure 2 shows that a renter decides to stay renter only if the cyclical housing risk premium is significantly negative and decide to assume ownership if it is positive and even when it is slightly negative.

Case 1: renter stays renter. If the cyclical housing risk premium is significantly negative, a renter decides to stay a renter. In such a bad housing market state, the renter anticipates falling house prices so that he is less inclined to postpone consumption into the future. The household does also not need to build up the minimum equity required to buy a home in the near future

\footnotetext{
${ }^{9}$ This value corresponds to the average labor income-wealth ratio at age 35 from 10,000 simulations on the optimal paths.
} 
because the persistence of the housing market cycle makes it a bad investment for a couple of years. As such, the graph shows that households increase the consumption of the non-durable good and the consumption of the home. That is the renter prefers to rent a larger home instead of buying one.

Since we assume a positive correlation $\left(\rho_{\xi L}=0.2\right)$ between shocks in the cyclical housing risk premium and labor income shocks, it is likely that housing market slumps and labor market slumps (decreases in $\xi$ and decreases in $L$ ) occur simultaneously. In these situations the increasing normalized home size and consumption ratio stabilize absolute consumption levels. It also becomes apparent that previous renters decide to stay in their home if the previous home size is close enough to the optimal one. In these situations the renter decides to avoid transaction costs since the implied cost of a suboptimal home size is smaller. Further, the renter can compensate a smaller or larger home with higher or smaller consumption ratios. Finally, the renter will have a diversified financial portfolio between stocks and bonds.

Case 2: renter stays renter. For high housing risk premiums a previous renter decides to become an owner. Hence, this result shows that housing market cycles have a strong impact on the homeownership decision of households whereas models assuming i.i.d. house price returns like e.g. Yao and Zhang (2005) report homeownership rates of $100 \%$ over large parts of the household's life cycle. Our result is a direct consequence of the strong degree of serial correlation in housing returns and its statistical significance. Further, this result can also be documented empirically with an OLS regression of annual U.S. homeownership rates $R_{o w n, t}$ from the U.S. Census Bureau on past annual Case-Shiller Index returns $r_{\text {house }, t-1}$ using data from 1968 to 2009 yields the equation ( $\mathrm{t}$-values in parentheses):

$$
R_{\text {own }, t}=\underset{(844.0964)}{0.6472}+\underset{(18.3045)}{0.1121} \cdot r_{\text {house }, t-1}+\epsilon_{t}
$$

The $R^{2}$ for this regression is 0.5868 .

The bought home size increases substantially with the cyclical housing risk premium since households decide to leverage the risk premium in order to accumulate wealth. In case the premium is at around $20 \%$, the purchased home is more than two times larger then the rented home in states with negative cyclical housing risk premium. The home is financed by a mortgage which has to be paid for with a reduction in the consumption rate by about two to three percentage points. In turn, the higher the cyclical housing risk premium the higher is the 
willingness to postpone consumption and to substitute the non-durable good with a large owned home. It also becomes apparent that the higher the cyclical housing risk premium is, the lower is the optimal equity exposure. While it is around $40 \%$ for low cyclical housing risk premiums it decreases to $0 \%$ for very high premiums. The reason for this finding is that the speculative demand for stocks is crowded out by the demand for house property. This important result might contribute to the literature seeking to explain the puzzling empirical evidence of low equity exposures and low stock market participation rates (Koyotaki et al. (2008)).

\section{Please insert Figure 3 about here.}

Case 3: Owner stays owner. Figure 3 focuses on the optimal behavior of a household which so far has owned its home. Such an owner has three options: 1) to stay in his home, 2) to stay owner, but to change the home size, and 3) to become a renter. This flexibility is affected substantially by transaction costs for owners that are so high that it is for many states optimal to stay in the same home even if the optimal home size (in the absence of transaction costs) would be substantially different. The figure makes apparent that it is likely that the owner decides to stay in the same home unless the housing risk premium is very low. In case the retained home size is somewhat too small, the household compensates the lack of present utility with higher consumption ratios and the forgone cyclical housing risk premium with higher equity exposures. If the home size is actually too large, the opposite is true so that the household might reduce consumption rates to low levels in order to stay in the same home.

Case 4: Owner becomes renter. The main reason for being forced to abandon and owned home is when the cyclical housing risk premium is very small so that the home owner expects a deep housing market slump. This decision is not only triggered by the short term expectation but also the medium term expectation since the half-life of cycles is expected to be 4.7 years. In case of a moderate housing market slump (i.e. slightly negative expected cyclical risk premium) the owner stays in its home and tolerates expected declines in housing wealth for some years since incurring the transaction costs would be even worse. This is especially true if the housing wealth is relatively low. If housing wealth has already been above its desired level, the owner is more inclined to sell its home since he cannot tolerate to experience a housing market slump with a highly leveraged housing investment. 


\subsection{Monte Carlo Simulation of a Complete Life Cycle}

This section discusses how housing market cycles affect the expected evolution of consumption, investments and the household's wealth level over the life cycle. We conduct a Monte Carlo simulation to obtain 10,000 paths for optimal consumption, housing and investment strategies.

Please insert Figure 4 about here.

In Figure 4 we plot the evolution of the household's average total wealth, housing wealth, stock investments, and bond/mortgage holdings for our base case parameter setting as a multiple of the initial labor income at age 20. The household's initial wealth level at age 20 is set to 1, i.e. the household is just endowed with the initial labor income.

In line with recent work by e.g. Cocco et al. (2005), it indicates the precautionary savings motive of households anticipating the drop in income by $30 \%$ when entering retirement. Hence households build up wealth until retirement by investing in stocks, bonds, and residential property. The amount of housing wealth dominates total wealth up to age 45. Only after that age financial wealth makes up more than $50 \%$ of total wealth. The rational is that households have a precautionary motive of buying a larger home at young age which will be sufficiently large to stay in for a long time so that moving costs are avoided.

Please insert Figure 5 about here.

Figure 5 depicts separately for owners and renters the evolution of the consumption rate $c$, the normalized home size $q$, the equity exposure, the exposure to bonds and mortgages (bond exposure), as well as the homeownership rate over the life cycle.

In general, the figure indicates that renters tend to consume a higher fraction of their wealth, tend to hold more equity, and tend to investment more heavily in bonds. These results are driven by the presence of housing market cycles and the borrowing constraint the household faces. At young age, the household is endowed with low financial wealth but high human capital from future labor income. For purchasing a home, however, he can only borrow against financial wealth, but not against his human capital. He therefore cannot afford to buy a home that is likely to still meet his requirements a few years ahead in time. Unless such an household faces a very attractive cyclical housing risk premium, he therefore remains a renter.

From the household's prime earning years on, this result reverses. Households already have accumulated significant financial wealth. For not sharply decreasing their financial wealth by 
substantial lease payments, renters optimally choose to live in smaller homes. Owners, at this age, however, on average live in slightly larger homes than renters. In addition to utility from the property of the home as a durable consumption good, these households seek to also benefit from the home as an investment good. Especially in states with desirable cyclical housing risk premiums, the home's investment character increases in relevance, causing the household to invest a larger fraction of his wealth into its home.

A renter, however, does not benefit from increases in house prices and only benefits from the characteristics of the home as a durable consumption good. Consequently, this household does not have an incentive to speculate on desirable future housing returns and therefore, on average, chooses a slightly lower home size. Our results confirm the finding of Pellizon and Weber (2009) that older households tend to be overexposed to housing investments. To avoid moving costs, older households have to debt-finance their housing investments again - a pattern which somewhat resembles a reverse mortgage. However, in contrast to a true reverse mortgage contract, in our setting the household still bears the house price risk.

We observe, that renters have higher consumption rates than owners during their working life. At young age this is due to the fact that young households buying a home are usually borrowing constrained and therefore cannot afford a higher consumption level. During the household's prime earning years, this is due to the fact that owners usually choose larger home sizes. Since consumption and the size of the home the household lives in are substitutes, the household partly substitutes consumption with a larger home.

The exposure to equity is systematically lower for owners than for renters. As already mentioned in $\mathrm{Hu}(2005)$ and Yao and Zhang (2005) this is caused by a substitution effect. Given that both housing and stock investments are risky, renters not investing into housing substitute for this by investing more heavily into stocks. For both owners and renters, we observe a significant increase in the optimal equity exposure when attaining retirement age. Again, this increase is due to the fact that in contrast to labor income, social security benefits are no longer subject to shocks. While during working age, correlation between labor income and the return on equity is positive, social security benefits and the return on equity are uncorrelated. This decrease in correlation increases the desirability of holding equity and therefore causes the household to increase his equity exposure.

The exposure to bonds differs remarkably for owners and renters. Given that only home owners can use their homes as collaterals, this is not surprising. We observe that home owners 
on average choose substantial leverages at young age whereas they on average manage to pay their debt off during their prime earning years. During retirement, however, home owners tend to increase their debt again. This is due to the fact that during retirement households run down their wealth quickly, as already seen in Figure 4, implying that the fraction of wealth held in the home is increasing.

\subsection{The Short and Long-run Effects of Housing Market Cycles}

Having studied the effect of housing market cycles on the evolution of consumption, portfolio choice and housing decisions over the life cycle, we now turn to illustrating how external shocks in housing market cycles affect consumption, housing and investment decisions as well as homeownership rates over the life cycle. In order to do so, we perform an impulse response analysis and shock the cyclical housing risk premium in all of the 10,000 simulated paths at age $30{ }^{10}$ In particular, we show that our model is able to predict short and long-run household behavior in terms of homeownership rates, equity exposures, leverages and consumption levels during and after housing market booms as well as busts.

\subsubsection{Housing Market Boom}

We begin our impulse response analysis by considering a positive shock in the cyclical housing risk premium $\lambda_{H}$ by 8.6 percentage points, which represents a housing market boom. Shocking the $\lambda_{H}$-value allows us to study how housing market booms affect consumption, portfolio and housing decisions and whether these effect are wiped out within few periods or have long-run effects. Figure 6 shows the evolution of average real consumption, home size, equity and bond holdings as well as the homeownership rate and the evolution of housing wealth. To assess whether owners or renters might react to a housing market boom in a different manner, we report separately results for households that are owners and renters before trading at age 30 .

Please insert Figure 6 about here.

In line with empirical evidence, our model predicts an increase in the homeownership rate caused by the housing market boom. Despite the mean reverting property of the housing market cycle, our results clearly indicate that a housing market boom positively affects homeownership rates over a longer time horizon, which is mainly caused by two effects. First, the half-life of the

\footnotetext{
${ }^{10}$ We also computed results for shocks at other ages. Given that these results did not differ qualitatively from those we obtained when shocking at the age of 30 , we do not report them here in detail.
} 
housing market cycle is relatively long. Secondly, even if the housing market boom is over and the housing risk premium has reverted to its mean, the household may still be a home owner and has an incentive not to sell his home to avoid transaction costs.

Also in line with empirical data, a housing market boom results in an increase in the value of the home the household lives in and substantially increases his housing wealth. In particular, households that have previously been renters invest in housing to also benefit from the housing market boom. Furthermore, for households facing a housing market boom, housing wealth is growing at a faster rate over the next periods due to the long half-life of the housing market cycle.

At the same time, housing market booms affect consumption and investment strategies. As an immediate reaction to the housing market boom, both owners and renters are subject to a substitution effect. In order to finance large homes, they reduce their consumption. Within a few periods, however, these households on average consume more than households that have not experienced a housing market boom, a pattern which reflects the wealth effect resulting from the housing market boom. Similar effects can be observed for the equity and bond holdings.

In line with empirical evidence from the SCF, which indicates that the average fraction of wealth held in equity has been decreasing from $21.6 \%$ in 2001 to $18.0 \%$ in 2007 , our model predicts that equity is substituted with housing investments. In the long-run, however, the increasing housing wealth leads to an increase in absolute equity holdings.

\subsubsection{Housing Market Bust}

We next turn to studying how housing market busts affect consumption, housing and investment decisions over the life cycle. To do so, we consider a negative shock in the cyclical housing risk premium by -8.6 percentage points.

Please insert Figure 7 about here.

Our results in Figure 7 show that many results we saw in Figure 6 with a housing market boom are reversed when we consider a housing market bust. In line with empirical evidence, our model predicts a decline in the homeownership rate. Due to the long half-life of the housing market cycle and the transaction costs involved with transacting a home, the effect of a housing market bust affects homeownership rates over several decades. 
A decrease in the homeownership rate as a fraction to bad housing market cycles is also found empirically. According to data from the U.S. census bureau, the homeownership rate decreased from $68.4 \%$ in 2007 to $67.2 \%$ in 2009 . In general, home owners optimally decrease their housing wealth and deleverage their balance sheets. Due to the drop in wealth caused by the housing market busts, households have lower housing wealth and live in smaller homes over their entire life cycle. Households that are renters before trading at age 30, however, can even increase the size of the home due to the expected future decrease in their rents. At the same time, they increase their consumption level, reflecting the close relation between optimal housing and consumption policies. The increase in both the size of the home and the consumption level is caused by the falling rents and the less desirable investment opportunity set the household is facing. Within a few periods, however, the wealth effect dominates consumption and housing decisions and implies that both initial owners and renter are restricted to smaller homes and the empirically observed lower consumption level.

Our model predicts that as an immediate reaction to the housing market bust, both owners and renters increase their equity holdings. Similarly they reduce their leverage by reducing their mortgages and/or increasing their bond holdings. That is, households substitute housing wealth with equity and bonds. In the long-run, the wealth effect also dominates equity and bond holdings and implies that households that have experienced the housing market bust hold less equity and bonds.

\subsection{Welfare Analysis}

In order to assess the welfare implications of housing market cycles over the life cycle, it is helpful to compare our base-case setting with a case exhibiting i.i.d. house price returns. Assuming i.i.d. returns implies that households do not base their decisions on the current state of the housing market. In order to equalize the first two moments of the housing return distribution we set the i.i.d. case parameters to $\sigma_{H}=15 \%$ and $\beta=0$.

Please insert Figure 8 about here.

Figure 8 compares the evolution of absolute real levels of consumption, home value, equity and bond holdings and housing wealth as well as the homeownership rate in a world with market cycles (solid lines) with results in a world without market cycles (dotted lines). 
In order to partly separate the consumption and investment components of privately owned homes, we differentiate between home size, which measures the size of the home the household lives in, and housing wealth, which is the amount of wealth an owner has invested in his home. Housing wealth is zero for renters that do not purchase a home, whereas the home size always takes on a positive value. Home size is therefore a better proxy for the home as a durable consumption good, whereas housing wealth better proxies for the investment character.

In the absence of housing market cycles the homeownership rate is close to $100 \%$ for large parts of the investor's life cycle, much higher than in the base-case where around $80 \%$ of the 10,000 households own a home. The reason is that in the i.i.d. case the expected risk premium is constant which increases the desirability of housing investments because the i.i.d. case does not capture the risks of a persistently adverse housing market cycle.

Another striking effect of housing market cycles is that households on average manage to attain higher consumption levels and live in larger homes by exploiting these cycles, which accumulates in a significant wealth effect over the life cycle. This wealth effect also translates into higher equity and bond holdings in the setting with housing market cycles.

Given the the expected wealth and consumption levels in the case with cycles it is obvious that households can exploit the serial correlation beneficially for their welfare. However, this welfare increase is based on the assumption that housing market cycles exist. Despite the fact that the statistical significance for housing market cycles in the past is overwhelming, there remains a possibility that they will no longer exist in the future.

In the following, we investigate the welfare costs of two types of errors. First, we consider the type I error (wrong rejection of the null hypothesis that returns are predictable) where welfare loss are generated by ignoring existing cycles. Secondly, we study the type II error (fail to reject wrong null hypothesis) where welfare losses occur since households assume cycles when they actually do not exist. The type I error allows us to access the importance of integrating housing market cycles into life cycle housing, consumption and portfolio planning. The type II error allows us to assess welfare implications if housing markets would no longer be subject to cycles in the future. Welfare costs are computed in two steps. First, we compute welfare levels for each and every state in our grid when following the respective suboptimal policy. We then compare attainable certainty equivalent wealth level of the optimal and the respective suboptimal strategies with each other to compute welfare costs from suboptimal trading. Welfare costs are measured in percentage of present financial, housing and human wealth (future labor income), 
the investor is willing to give up to avoid having to trade under the respective suboptimal strategy that either erroneously ignores existing housing market cycles or falsely assumes the existence of non-existing cycles. That is, welfare costs can also be interpreted as percentage permanent decreases in consumption and home size the investor is willing to give up to avoid having to trade under a suboptimal strategy.

Please insert Figure 9 about here.

Figure 9 depicts the average expected welfare costs over the life cycle from 10,000 simulations on the respective optimal paths. For each path, the initial value for the cyclical housing risk premium is drawn from its stationary distribution. Our results show that welfare costs from ignoring existing cycles are substantial. First, households ignoring existing cycles (dashed line) fail to exploit housing market booms by not increasing their home size to benefit from increasing house prices. Secondly, households underestimate the risk of persistent bad housing market cycles so that they keep their homes during housing market slumps. This risk is especially pronounced for younger households with lower wealth levels that finance their homes with high leverage ratios and run the risk of experiencing large losses when ignoring housing market cycles. Thirdly, not adjusting the home size to circumstances implies second-order effects via the choice of suboptimal consumption, equity and bond policies. These welfare effects are partly offset by the lower trading frequency of the home and the thereby saved transaction costs.

The welfare loss of households assuming housing market cycles when they do not exist are shown in the solid line. Such a household uses signals that do not contain any information to predict housing returns and act as if these signals would contain information about the cyclical housing risk premium. Therefore, the household might falsely sell (buy) a home because it assumes that the bad (good) housing market cycle is persistent, assuming the half-life of cycles of 4.7 years estimated above. Hence welfare losses are generated since the household incurs avoidable moving costs and is exposed to too much house price risk when it predicts a good cycle and too less house price risk when it predicts a bad cycle. In particular, this household also faces an increased risk of higher losses from leveraged housing investments. In addition, our results in Figures 2 and 3 show, that consumption, equity and bond policies are also affected, which results in additional welfare effects. Taken together, these effects result in the depicted welfare costs. 
In total, our results show that ignoring housing market cycles in life cycle consumption, housing, and portfolio decisions results in seizable welfare costs and tend to exceed welfare costs from erroneously assuming non-existing cycles. It seems likely that households consider the state of the housing market in their decisions. Two reasons speak for this. First, households have experienced the statistically significant serial correlation in housing returns and secondly, welfare losses are too large to be ignored.

\section{Robustness Analysis}

In this section, we study how optimal policies are affected by changes in parameter assumptions. We will focus on three settings.11 First, we study a setting, where we increase the correlation between housing and stock market risk to $\rho_{S H}=0.5$. This allows us to investigate how consumption, housing and portfolio policies are affected by decreased diversification potential. Secondly, we study a scenario, where we increase the correlation between housing and labor income risk to $\rho_{H L}=0.5$, an order of magnitude which can be found in local housing markets (Davidoff (2006)). Thirdly, we investigate a scenario in which we set $\kappa$, our mean-reversion parameter in the house price process to the sum of its estimated value and its estimated standard deviation, i.e. $\kappa=0.2922$. This decreases the half-life of shocks in the housing market to about 2.4 years, thereby allowing us to assess the importance of the duration of housing markets cycles for optimal consumption, housing and investment strategies over the life cycle.

Table 3 shows averages and standard deviations for the household's consumption rate $c$ (consumption), the normalized home size $q$ as well as the fraction of wealth invested held in stocks (equity exposure) and bonds (bond exposure). It further shows homeownership rates. All results are based on 10,000 simulations on the respective optimal paths. Results are shown separately for owners and renters.

Please insert Table 3 about here.

Our results show that an increase in correlation between changes in stock and house prices $\left(\rho_{S H}=0.5\right)$ decreases the average home size for owners, decreases the homeownership rate and increases the owners' equity exposure compared to our base case parameter setting. Owners' consumption policies and bond exposures, on the other hand, are not much affected.

\footnotetext{
${ }^{11}$ Besides the results reported here, we, among others, also studied settings in which we introduced a bequest motive. Given that for reasonable levels of its strength, our results were not much affected, we did not report these results here.
} 
With increased correlation between stock and housing market risk, it becomes more difficult to diversify these two risks. As a consequence, households are somewhat less likely to become home owners and, conditional on becoming owners, the average fraction of wealth invested in a privately owned home is smaller. At the same time, owners tend to increase their average exposure to equity. That is, they substitute housing for stock market risk. Whereas with lower correlation between stock and housing market risk a lower exposure to equity is sufficient to attain a reasonable level of diversification, an increased level of correlation requires a higher exposure to equity to attain a reasonable level of diversification.

For renters that are less exposed to housing market risk, we primarily observe an increased correlation between stock and housing market risk to affect the households' exposure to equity and bonds. With increased correlation renters are a lot more exposed to equity. The higher correlation between stock and housing market risk allows them to better hedge against rent price risk by increasing their exposure to equity.

The columns marked $\rho_{H L}=0.5$ show how a higher correlation between housing and labor income risk affect consumption, housing and investment policies for owners and renters. The increased level of correlation increases the risk of simultaneous housing and labor market slumps substantially, thereby making in particular leveraged housing investments more risky. As a consequence, we observe a substantially lower homeownership rate than in our base case parameter setting. Conditional on owning a home, the optimal average amount invested in it, is not much affected. However, we observe higher consumption rates and higher mortgage holdings at young age. That is, at young age households are more willing to finance part of their consumption by using their home as a collateral.

For renters we observe effects similar to those for owners. At young age, consumption rates are higher and bond exposures are lower. In addition, renters increase their equity exposures and the size of their home.

With increased correlation between labor and housing market risk, labor income provides a better hedge against house price risk, which allows renters to choose larger home sizes. The higher lease expenditures combined with the higher immediate consumption result in a lower wealth level and thereby a higher labor income-wealth ratio. As labor income mimics the payment stream from a coupon-bearing bond, our household optimally reduces his exposure to bonds and increases his exposure to equity.

Our setting with lower half-life of housing market cycles $\left(\kappa=\mathbb{E}[\kappa]+\sigma_{\kappa}=0.2922\right)$ shows that 
the decreased long-run risk in housing markets results in a significantly higher homeownership rate. At the same time, the average home size for owners decreases slightly, reflecting the on average reduced importance of the desire to exploit housing market cycles. With on average shorter housing market cycles, households are also more willing to stay owners for somewhat less desirable housing risk premiums to avoid transaction costs. As these households tend to hold smaller homes than households trying to exploit desirable housing risk premiums, the optimal average home size decreases. Furthermore, households facing desirable housing risk premiums may expect these premiums to revert faster to their mean than in our base case parameter setting.

For renters, the exposure to stocks and bonds is most affected by housing market cycles. Essentially, the lower half-life of housing market cycles causes renters to decrease their exposure to equity and increase their exposure to bonds. This reflects that households are more likely to be renters in bad states of the housing market cycles. As a consequence, renters may expect house prices to decrease. To increase chances of becoming owners in the future, these households hold more bonds when housing market cycles are shorter.

\section{Conclusion}

In this paper, we propose a new dynamic life cycle consumption, housing and portfolio problem when house prices are subject to housing market cycles and households receive unspanned stochastic labor income. We further endogenize the decision whether to own or rent, include transaction costs, and calibrate the house price process using Case-Shiller Home Price Index data. Our regression analysis as well as the calibration of the model has shown that serial correlation in annual returns of the Case-Shiller Home Price Index data from 1954 to 2009 is highly significant (t-value 18.9) and that the regression explains more than $50 \%$ of the variability in housing returns.

Since households in the U.S. have experienced this house price pattern for a long time during their life cycles, it is likely that they have been trained to base their decisions also on the state of the housing market cycle. Especially the experience that house prices have risen for a long time made them aware that exploiting positive housing market cycles can be profitable. Given that the housing investment is usually the largest investment of households, and affects consumption and portfolio choice decisions, it is important to understand how housing market cycles affect 
household decision making.

While earlier studies showed that homeownership mainly serves the consumption and the precautionary savings motive, our model additionally predicts a speculative demand for housing investments. The key result is that households do not only base their decisions on labor-income, wealth, and age, but also on the currently anticipated state of the housing market, i.e. the level of the cyclical housing risk premium. Our life cycle utility optimization shows that the cyclical housing risk premium is an important new state variable in life cycle consumption and investment frameworks since optimal household decisions are highly sensitive to housing market cycles. Commensurate to empirical data, our model predicts that in good states of housing market cycles, households are more likely to be home owners, tend to live in larger homes, and finance their homes with higher leverage. With increasing house prices, households have to purchase stocks to keep their portfolios diversified, which should help understanding the positive empirically observed correlation between housing and stock returns. In states with negative housing market cycles, all these effects are reversed.

Our impulse response analysis predicts that significantly negative housing market shocks have long lasting effects not only on the housing investment itself, but also on consumption and portfolio choice. Particularly, it predicts that a recovery from a housing market slump may take several years. One reason is that households instantaneously try to manage risks by selling their homes and deleverage their balance sheets (if they are not already forced to do so by the minimum home-equity restriction) in times of bad housing market cycles so that there is ongoing pressure on the housing market. The destruction of housing wealth implies second round effects such as reduced consumption levels and stock investments which puts further stress on the economic situation.

Our welfare analysis shows that ignoring existing housing market cycles are seizable and tend to exceed those from assuming cycles when they actually do not exist. Welfare losses for the former type of household are especially severe if home owners underestimate the risk of an extended housing market slump so that they stay in their home and suffer potentially significant losses in their housing wealth. Wrongly assuming cycles is mainly costly because moving costs are incurred too often. A final robustness analysis confirms that our results are robust to various assumptions. 


\section{References}

Amromin, G., J. Huang, C. Sialm, and E. Zhong, 2010, "Mortgage Complexity and House Price Dynamics," working paper, University of Texas at Austin.

Ang, A., and G. Bekaert, 2007, "Stock Return Predictability: Is it There?" Review of Financial Studies, 20(3), 651-707.

Balduzzi, P., and A. W. Lynch, 1999, "Transaction Costs and Predictability: Some Utility Cost Calculations," Journal of Financial Economics, 52(1), 47-78.

Barberis, N., 2000, "Investing for the Long Run When Returns are Predictable," Journal of Finance, 55(1), 225-264.

Bodie, Z., R. C. Merton, and W. F. Samuelson, 1992, "Labor Supply Flexibility and Portfolio Choice in a Life Cycle Model," Journal of Economic Dynamics and Control, 16(3-4), 427-449.

Brennan, M. J., E. S. Schwartz, and R. Lagnado, 1997, "Strategic Asset Allocation," Journal of Economic Dynamics and Control, 21(8), 1377-1403.

Campbell, J. Y., 1987, "Stock Returns and the Term Structure," Journal of Financial Economics, 18(2), 373-399.

Campbell, J. Y., Y. L. Chan, and L. M. Viceira, 2003, "A Multivariate Model of Strategic Asset Allocation," Journal of Financial Economics, 67(1), 41-80.

Campbell, J. Y., and J. F. Cocco, 2007, "How do house prices affect consumption? Evidence from micro data," Journal of Monetary Economics, 54(3), 591-621.

Campbell, J. Y., and S. B. Thompson, 2008, "Predicting Excess Stock Returns Out of Sample: Can Anything Beat the Historical Average?" Review of Financial Studies, 21(4), 1509-1531.

Campbell, J. Y., and L. M. Viceira, 1999, "Consumption and Portfolio Decisions when Expected Returns are Time Varying," Quarterly Journal of Economics, 114(2), 433-495.

Case, K. E., J. M. Quigley, and R. J. Shiller, 2005, "Comparing Wealth Effects: The Stock Market versus the Housing Market," Advances in Macroeconomics, 5(1), 1-32.

Case, K. E., and R. J. Shiller, 1989, "The Efficiency of the Market for Single-Family Homes," American Economic Review, 79(1), 125-137. 
Cauley, S. D., A. D. Pavlov, and E. S. Schwartz, 2007, "Homeownership as a Constraint on Asset Allocation," Journal of Real Estate Finance and Economics, 34(3), 283-311.

Claus, J., and J. Thomas, 2001, "Equity Premia as Low as Three Percent? Evidence form Analysts' Earnings Forecasts for Domenstic and International Stock Markets," Journal of Finance, 56(5), 1629-1666.

Cocco, J., 2005, "Portfolio Choice in the Presence of Housing," Review of Financial Studies, $18(2), 535-567$.

Cocco, J. F., F. J. Gomes, and P. J. Maenhout, 2005, "Consumption and Portfolio Choice over the Life Cycle," Review of Financial Studies, 18(2), 491-533.

Constantinides, G. M., 1986, "Capital Market Equilibrium with Transaction Costs," Journal of Political Economy, 94(4), 842-862.

Corradin, S., J. L. Fillat, and C. Vergara-Alert, 2010, "Optimal Portfolio Choice with Predictability in House Prices and Transaction Costs," working paper.

Damgaard, A., B. Fuglsbjerg, and C. Munk, 2003, "Optimal Consumption and Investment Strategies with a Perishable and an Indivisible Durable Consumption Good," Journal of Economic Dynamics and Control, 28(2), 209-253.

Davidoff, T., 2006, "Labor Income, House Prices, and Homeownership," Journal of Urban Economics, 39, 209-235.

Davis, M., and A. Norman, 1990, "Portfolio Selection with Transaction Costs," Mathematics of Operations Research, 15(4), 676-713.

Fama, E. F., and K. R. French, 1989, "Business Conditions and Expected Returns on Stocks and Bonds," Journal of Financial Economics, 25(1), 23-49.

Flavin, M., and T. Yamashita, 2002, "Owner-Occupied Housing and the Composition of the Household Portfolio," American Economic Review, 92(1), 345-362.

Fluck, Z., B. G. Malkiel, and R. E. Quandt, 1997, "The Predictability of Stock Returns: A Cross-Sectional Simulation," Review of Economics and Statistics, 79(2), 176-183.

Gomes, F., and A. Michaelides, 2005, "Optimal life-cycle Asset Allocation: Understanding the empirical Evidence," Journal of Finance, 60(2), 869-904. 
Grossman, S. J., and G. Laroque, 1990, "Asset Pricing and Optimal Portfolio Choice in the Presence of Illiquid Durable Consumption Goods," Econometrica, 58(1), 25-51.

Hu, X., 2005, "Portfolio Choices for Homeowners," Journal of Urban Economics, 58(1), 114-136.

Kandel, S., and R. F. Stambaugh, 1996, "On the Predictability of Stock Returns: An AssetAllocation Perspective," Journal of Finance, 51(2), 385-424.

Koyotaki, N., A. Michaelides, and K. Nikolov, 2008, "Winners and Losers in Housing Markets," working paper.

Kraft, H., and C. Munk, 2010, "Optimal Housing, Consumption, and Investment Decisions over the Life-Cycle," working paper.

Lanne, M., 2002, "Testing the Predictability of Stock Returns," Review of Economics and Statistics, 84(3), 407-415.

Leland, H. E., 2001, "Optimal Portfolio Implementation with Transactions Costs and Capital Gains Taxes," working paper, University of California at Berkeley.

Li, W., and R. Yao, 2007, "The Life-Cycle Effects of House Price Changes," Journal of Money, Credit and Banking, 39(6), 1375-1409.

Liu, J., 2007, "Portfolio Selection in Stochastic Environments," Review of Financial Studies, 20(1), 1-39.

Lynch, A. W., 2001, "Portfolio Choice and Equity Characteristics: Characterizing the Heding Demand Induced by Return Predictability," Journal of Financial Economics, 62(1), 67-130.

Lynch, A. W., and P. Balduzzi, 2000, "Predictability and Transaction Costs: The Impact on Rebalancing Rules and Behavior," Journal of Finance, 55(5), 2285-2309.

Lynch, A. W., and S. Tan, 2009, "Multiple Risky Assets, Transaction Costs and Return Preditability: Allocation Rules and Implications for U.S. Investors," Journal of Financial and Quantitative Analysis, forthcoming.

Muthuraman, K., and S. Kulmar, 2006, "Multidimensional Portfolio Optimization with Proportional Transaction Costs," Mathematical Finance, 16(2), 301-335. 
Pellizon, L., and G. Weber, 2009, "Efficient Portfolios when Housing needs Change over the Life Cycle," Journal of Banking and Finance, 33, 2110-2121.

Pesaran, M., and A. Timmermann, 1995, "Predictability of Stock Returns: Robustness and Economic Significance," Journal of Finance, 50(4), 1201-1228.

Schroder, M., and C. Skiadas, 1999, "Optimal Consumption and Portfolio Selection with Stochastic Differential Utility," Journal of Economic Theory, 89(1), 68-126.

Schroder, M., and C. Skiadas, 2003, "Optimal Lifetime Consumption-Portfolio Strategies under Trading Constraints and Generalized Recursive Preferences," Stochastic Processes and their Applications, 108(2), 155-202.

Van Hemert, O., 2010, "Household Interest Rate Risk Management," Real Estate Economics, $38(3), 467-505$.

Viceira, L. M., 2001, "Optimal Portfolio Choice for Long-Horizon Investors with Nontradable Labor Income," Journal of Finance, 56(2), 433-470.

Yamashita, T., 2003, "Owner-occupied Housing and Investment in Stocks: An Empirical Test," Journal of Urban Economics, 53(2), 220-237.

Yao, R., and H. H. Zhang, 2005, "Optimal Consumption and Portfolio Choices with Risky Housing and Borrowing Constraints," Review of Financial Studies, 18(1), 197-239.

Yao, R., and H. H. Zhang, 2008, "Optimal Life-Cycle Asset Allocation with Housing as Collateral," working paper. 


\section{A Computation of certainty equivalents}

$$
\begin{aligned}
U & =\int_{0}^{T} \beta^{-s} u\left(C_{s}, Q_{s}\right) d t \\
& =\int_{0}^{T} \beta^{-s} \frac{\left(C_{s}^{1-\psi} Q_{s}^{\psi}\right)^{1-\gamma}}{1-\gamma} d t
\end{aligned}
$$

In the absence of transaction costs, the optimal relation between home size $Q$ and consumption $C$ is given by $Q=C \frac{\psi}{1-\psi} \frac{1}{\xi_{\text {rent }}}$. Plugging this relation in, one obtains

$$
\begin{aligned}
U & =\int_{0}^{T} \delta^{-s} \frac{\left(C_{s}^{1-\psi}\left(C_{s} \frac{\psi}{1-\psi} \frac{1}{\xi_{\text {rent }}}\right)^{\psi}\right)^{1-\gamma}}{1-\gamma} d t \\
& =\int_{0}^{T} \delta^{-s} \frac{\left(C_{s}\left(\frac{\psi}{1-\psi} \frac{1}{\xi_{\text {rent }}}\right)^{\psi}\right)^{1-\gamma}}{1-\gamma} d t \\
& =\int_{0}^{T} \delta^{-s} \frac{C_{s}^{1-\gamma}\left(\frac{\psi}{1-\psi} \frac{1}{\xi_{\text {rent }}}\right)^{\psi(1-\gamma)}}{1-\gamma} d t \\
& =\frac{\left(\frac{\psi}{1-\psi} \frac{1}{\xi_{\text {rent }}}\right)^{\psi(1-\gamma)}}{1-\gamma} \int_{0}^{T} \delta^{-s} C_{s}^{1-\gamma} d t
\end{aligned}
$$

That is, if $U_{\text {pred }}=\frac{\left(\frac{\psi}{1-\psi} \frac{1}{\xi_{r e n t}}\right)^{\psi(1-\gamma)}}{1-\gamma} \int_{0}^{T} \delta^{-s} C_{s, \text { pred }}^{1-\gamma} d t$ and $U_{\text {nopred }}=\frac{\left(\frac{\psi}{1-\psi} \frac{1}{\xi_{r e n t}}\right)^{\psi(1-\gamma)}}{1-\gamma} \int_{0}^{T} \delta^{-s} C_{s, \text { nopred }}^{1-\gamma} d t$ it holds that

$$
\frac{C_{\text {pred }}}{C_{\text {nopred }}}=\left(\frac{U_{\text {pred }}}{U_{\text {nopred }}}\right)^{\frac{1}{1-\gamma}}=\left(\frac{U_{\text {nopred }}}{U_{\text {pred }}}\right)^{1-\gamma}
$$



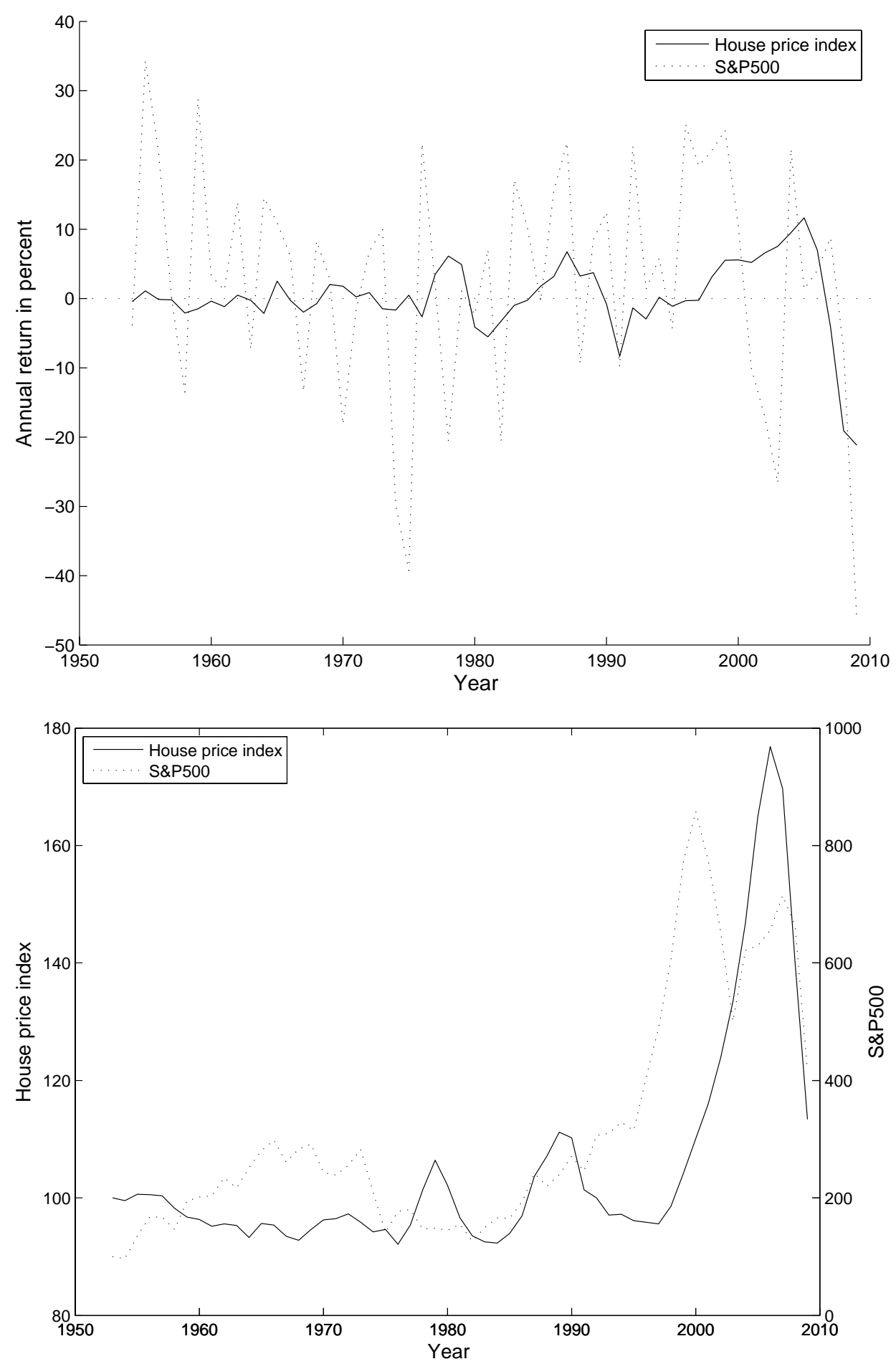

Figure 1: Historical evolution of stock and house prices: This figure depicts the historical annual real log-returns (upper graph) and index levels (lower graph) for the Case-Shiller house price index and the S\&P500 index from 1954 to 2009. 


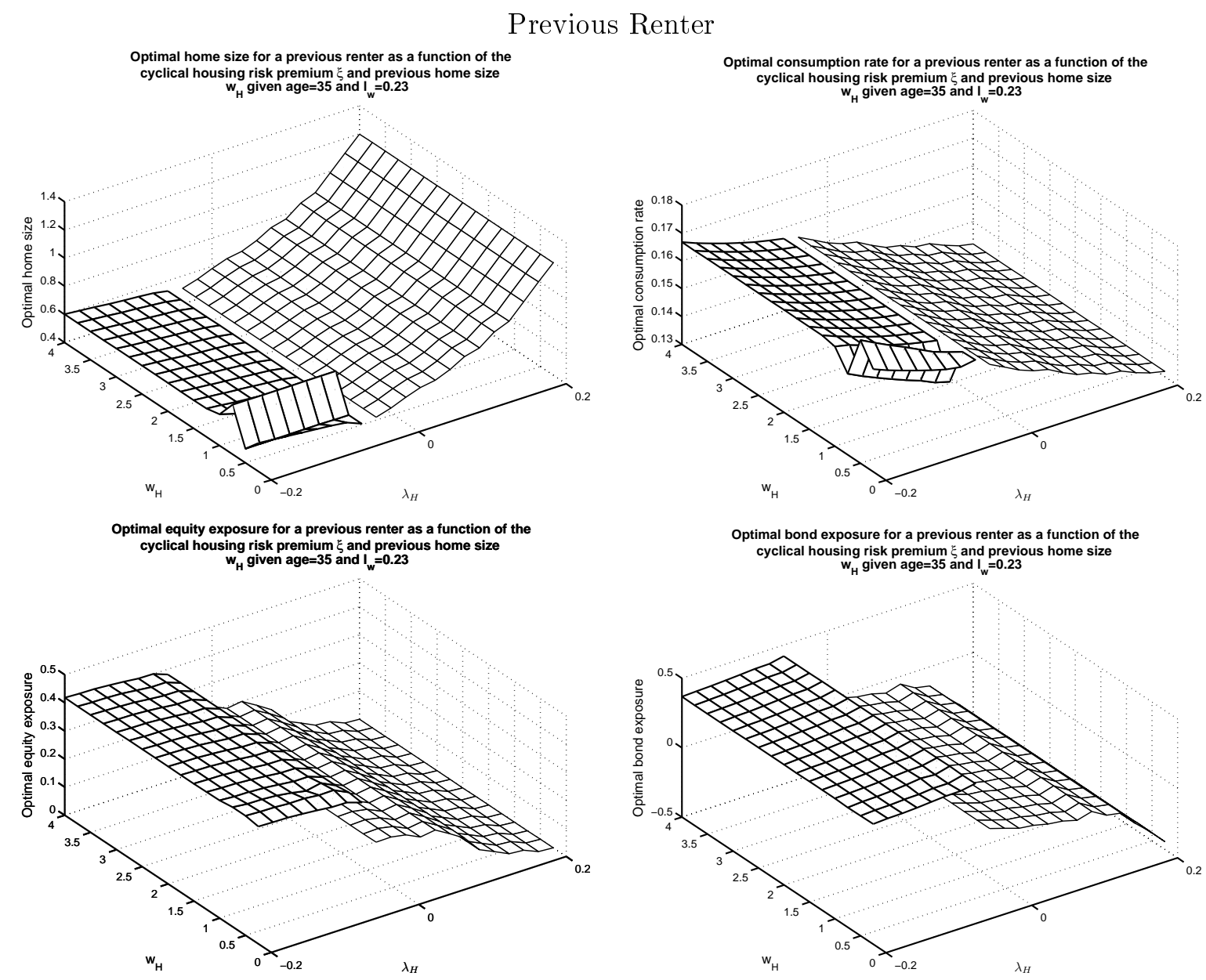

Figure 2: Optimal policies renter: This figure depicts the optimal policies as a function of the cyclical housing risk premium $\lambda_{H}$ and the previous home size $w_{H}$ for households who have been previously renting their home. Policy functions are presented for households aged 35 and with labor income-wealth ratio of $l_{w}=0.23$. The surface with thick (thin) lines indicates the area in which the households decides to rent (own) the home. 


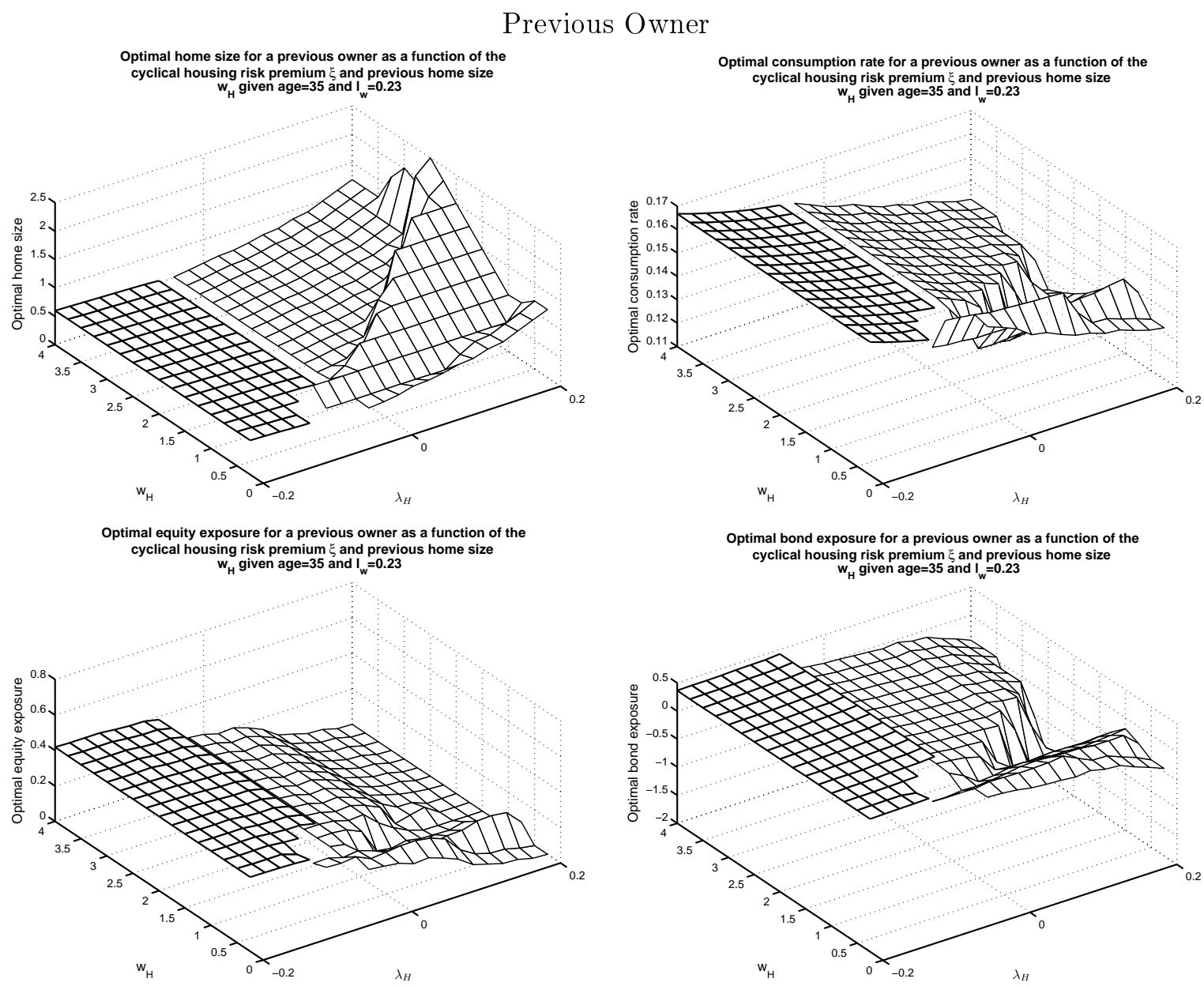

Figure 3: Optimal policies owner: This figure depicts the optimal policies as a function of the cyclical housing risk premium $\lambda_{H}$ and the previous home size $w_{H}$ for households who have been previously owning their home. Policy functions are presented for households aged 35 and with labor income-wealth ratio of $l_{w}=0.23$. The surface with thick (thin) lines indicates the area in which the households decides to rent (own) the home. 


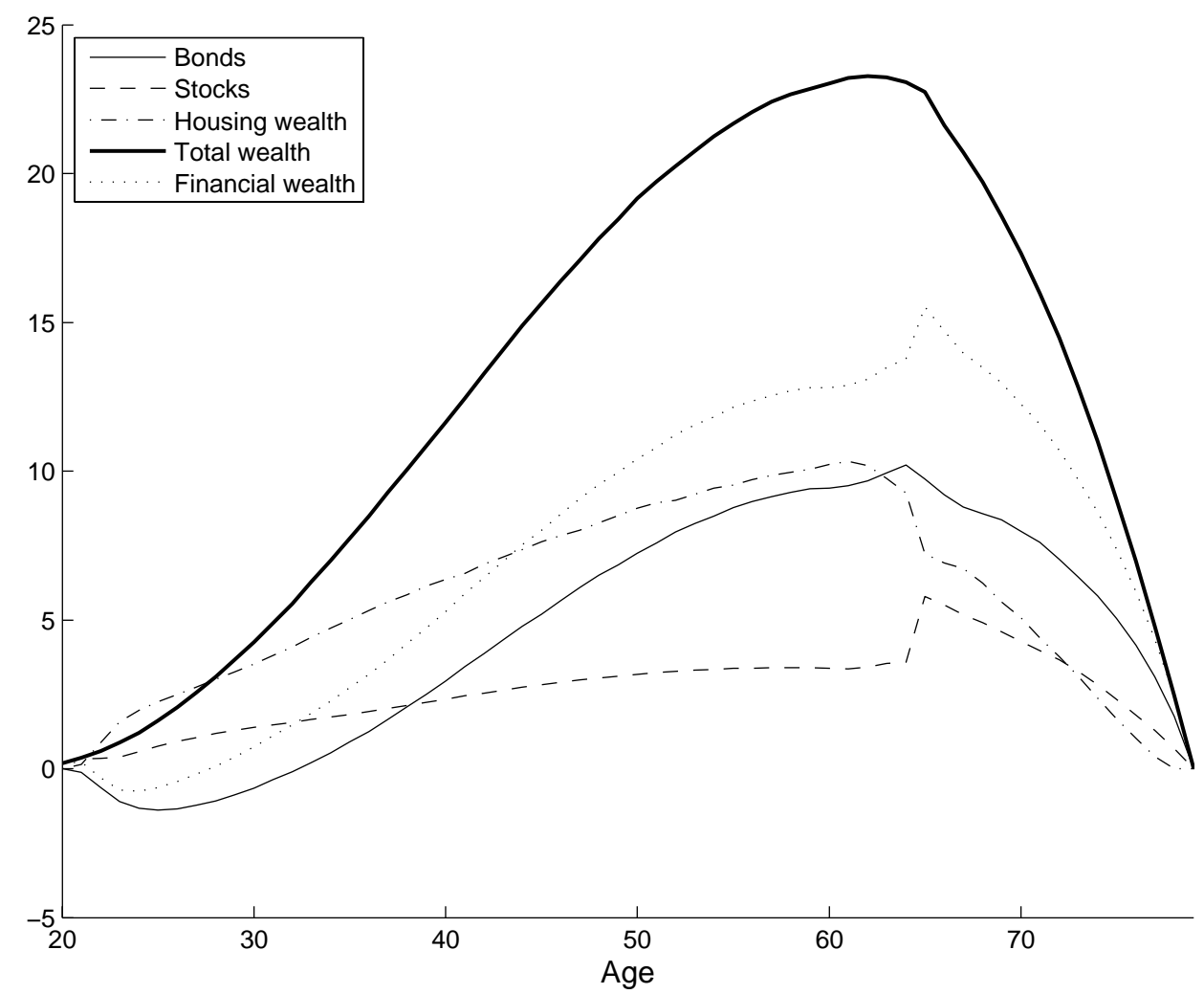

Figure 4: Life cycle profile: This figure plots the evolution of the household's average total wealth, housing wealth, financial wealth, stock investments, and bond/mortgage holdings from 10,000 simulations on the optimal paths for our base case parameter setting. 

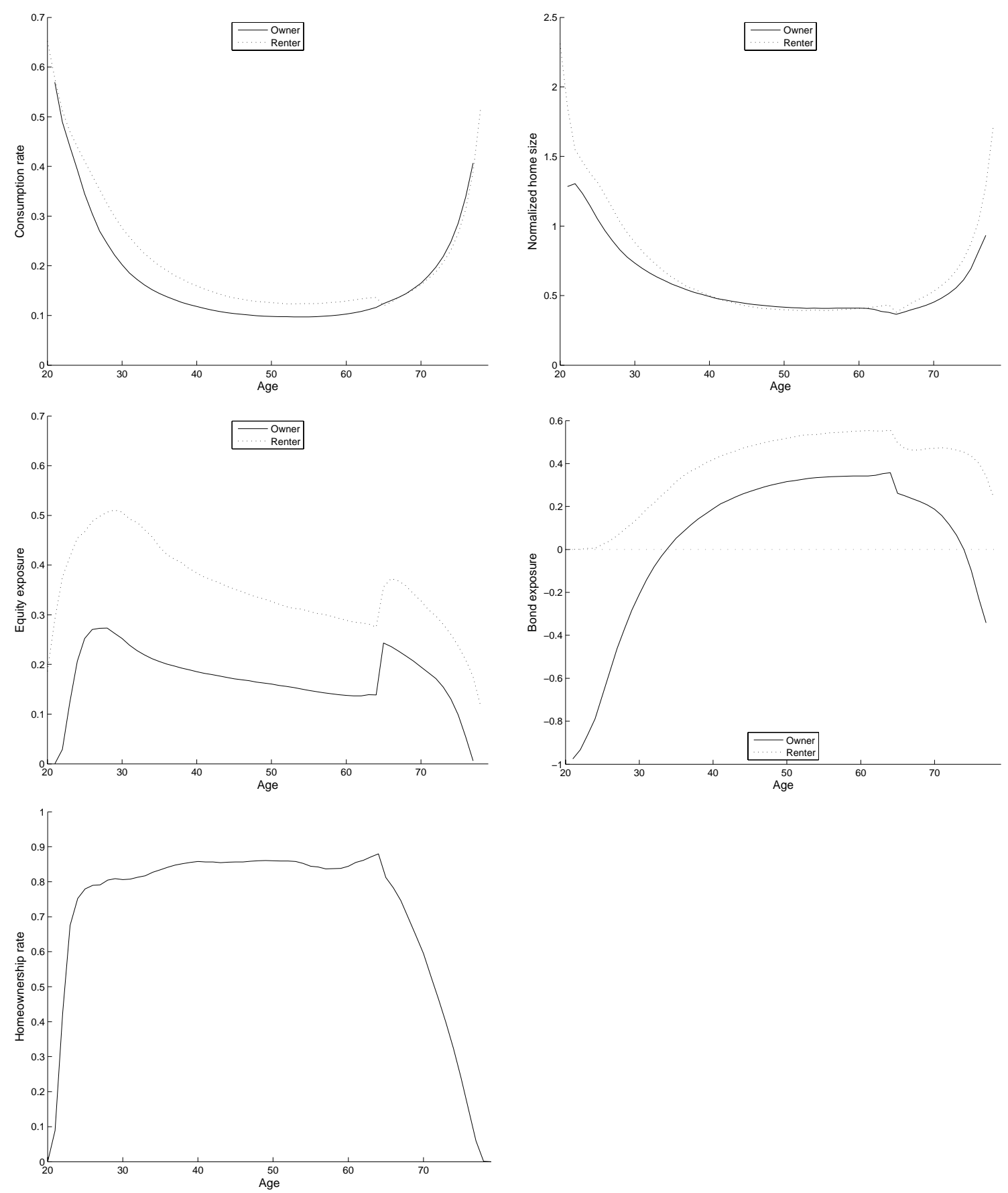

Figure 5: Evolution of consumption, investment, housing policies, and ownership rate; base case parameter setting: This figure shows average consumption, investment and housing policies over the life cycle for households being owner (solid lines) or renter (dotted lines) after trading at different ages. It further shows the evolution of the homeownership rate from these simulations. All results are based on 10,000 simulations on the optimal paths. Except for the homeownership rate, all results are expressed as fractions of wealth before trading and consumption. 

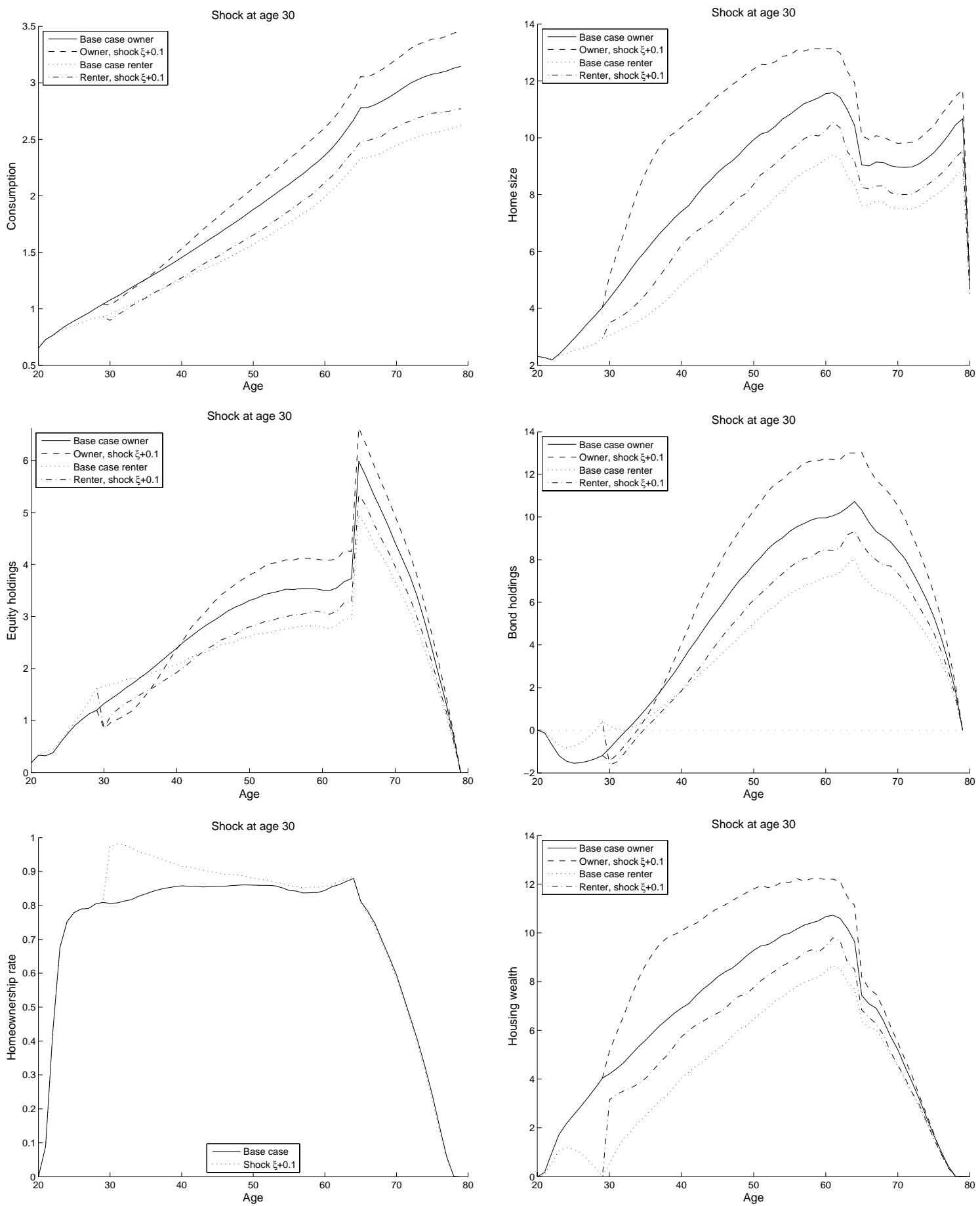

Figure 6: Impulse response analysis, positive shock in cyclical housing risk premium: This figure shows how a positive persistent housing market shock $\left(\lambda_{H}+0.086\right)$ affects the average evolution of the household's real consumption, investments and housing decisions over the life cycle compared to our base case setting. It is distinguished between households initially being owner or renter prior to trading at age 30 where the shock occurs. All results are based on 10,000 simulations on the respective optimal paths. 

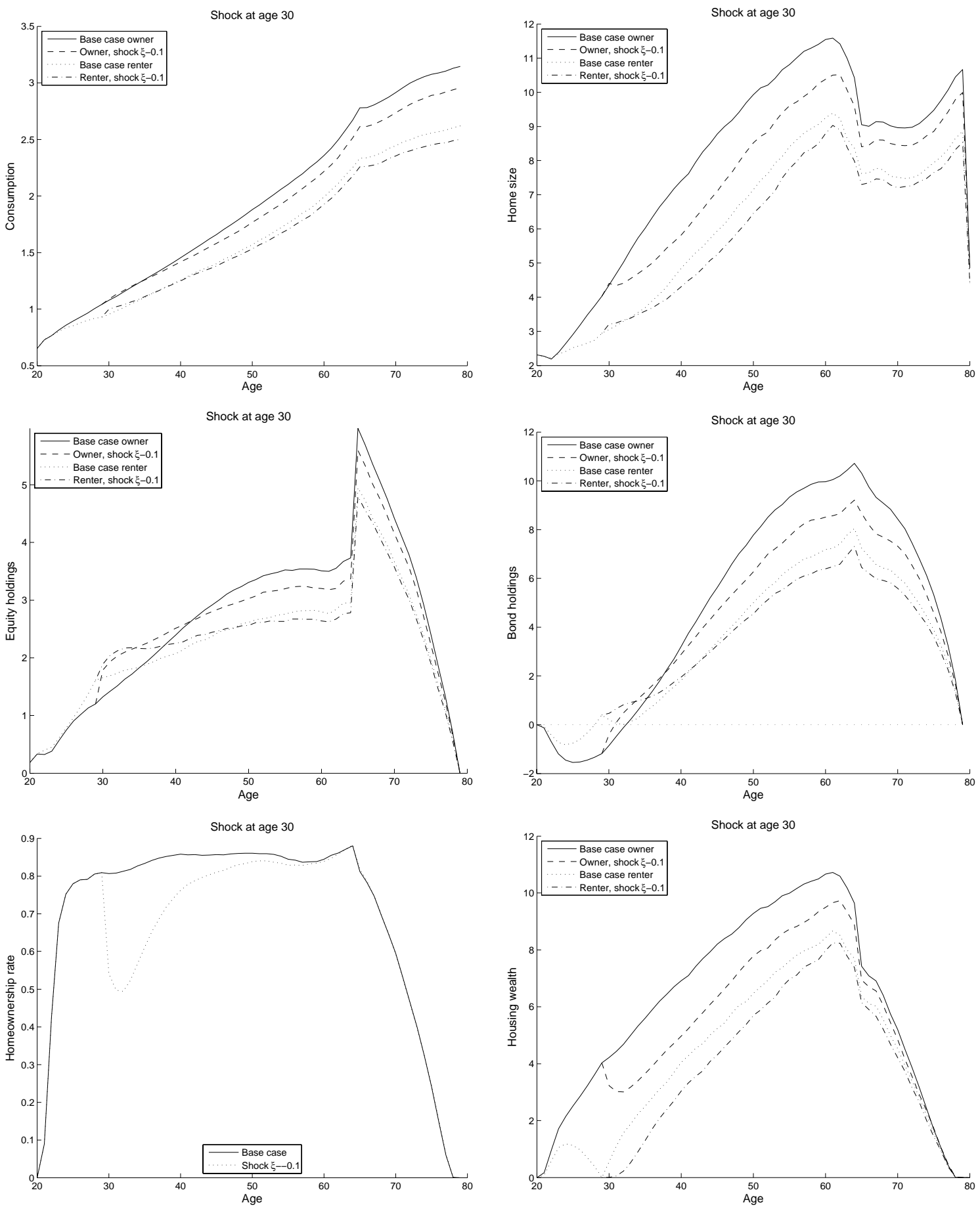

Figure 7: Impulse response analysis, negative shock in cyclical housing risk premium: This figure shows how a negative persistent housing market shock $\left(\lambda_{H}-0.086\right)$ affects the average evolution of the household's real consumption, investments and housing decisions over the life cycle compared to our base case setting. It is distinguished between households initially being owner or renter prior to trading at age 30 where the shock occurs. All results are based on 10,000 simulations on the respective optimal paths. 

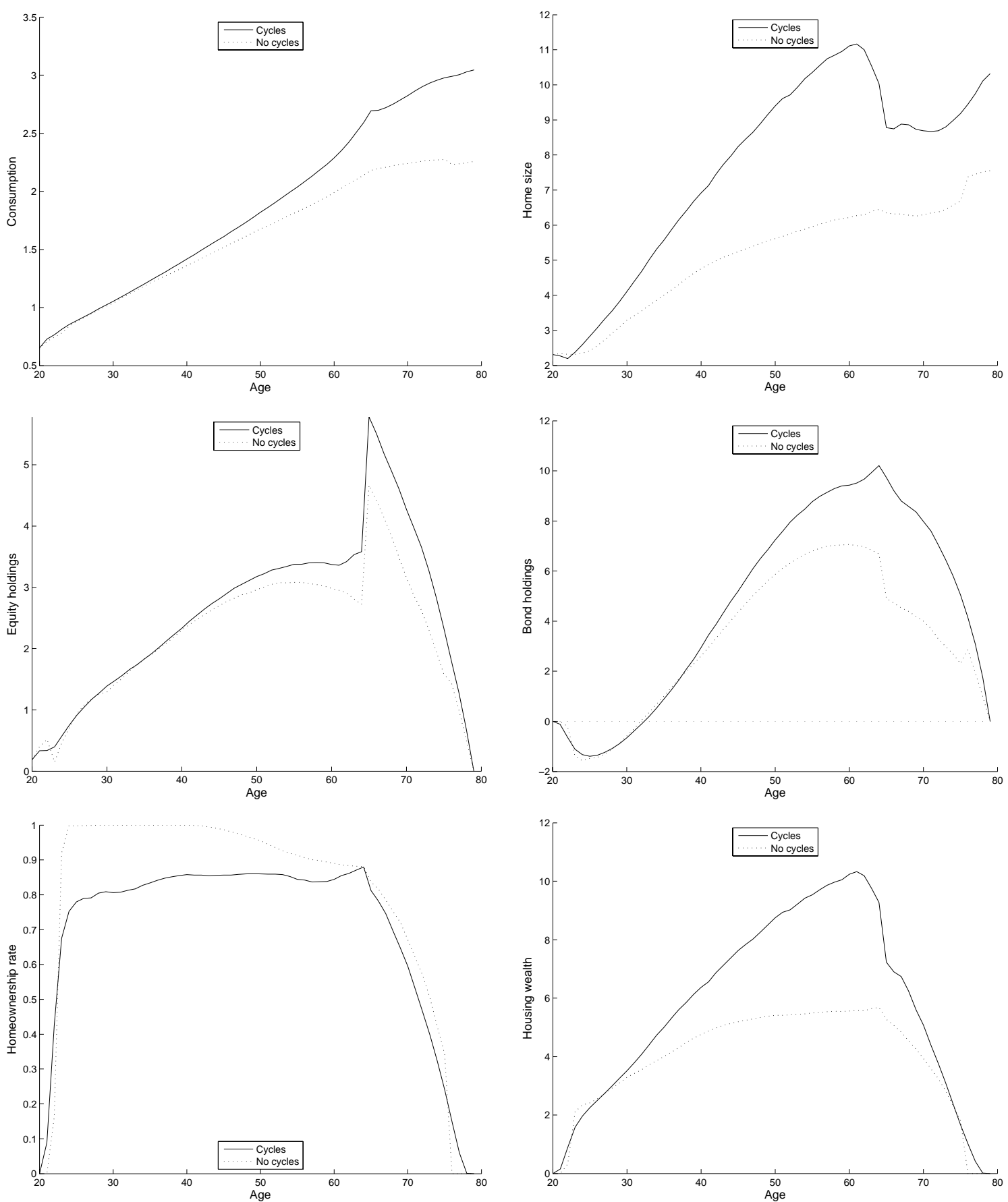

Figure 8: Impact of housing market cycles: This figure shows the average evolution of real consumption $C$, investment, size of the home the household lives in (home size) and housing wealth over the life cycle for both households trading in settings with housing market cycles (solid lines) and without (dotted lines). It further compares homeownership rates for these two settings. All results are based on 10,000 simulations on the respective optimal paths. 


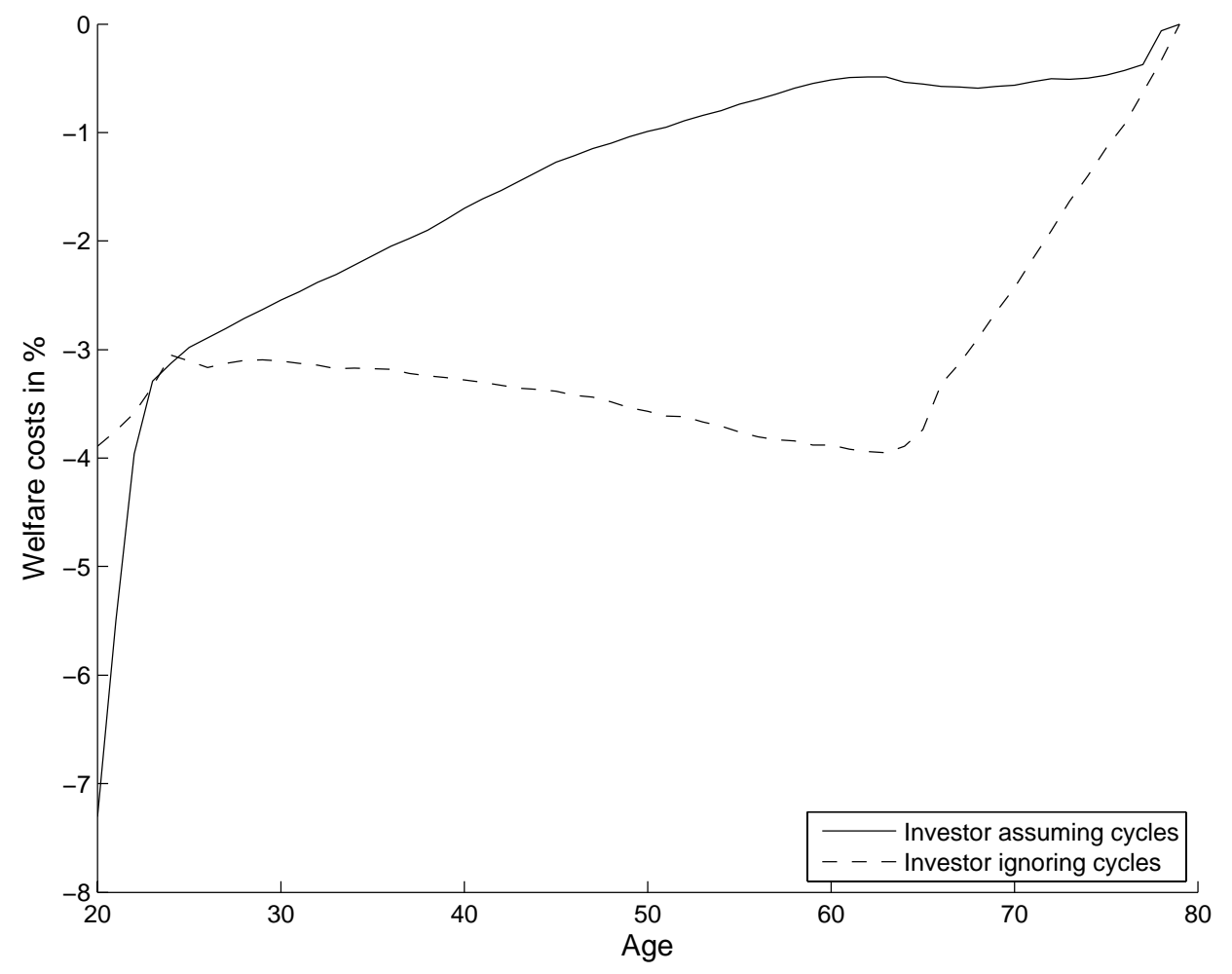

Figure 9: Welfare costs: This figure depicts the average welfare costs from 10,000 simulations over the life cycle of 1) trading in a setting without housing market cycles following the alternative policy derived in a setting with such cycles (solid line "household assuming cycles") and 2) trading in a setting with housing market cycles following the alternative policy derived in a setting without such cycles (dashed line "household ignoring cycles"). Welfare costs are measured as fraction of present financial wealth, housing wealth and human capital (future income) a household is willing to give up to avoid having to trade under the respective alternative policy. 


\begin{tabular}{lrr} 
Parameter & Estimate & Standard error \\
\hline$\kappa$ & 0.1478 & $(0.1444)$ \\
$\beta$ & 0.8567 & $(0.1034)$ \\
$\log \left(\frac{H_{t}}{H_{t-1}}\right)$ & 0.0022 & $(0.0547)$ \\
$\bar{\xi}$ & 0.0022 & $(0.0340)$ \\
$\sigma_{\xi}$ & 0.0405 & $(0.0069)$ \\
$\rho_{H \xi}$ & 0.9967 & $(0.0022)$ \\
$\sigma_{H}$ & 0.0374 & $(0.0125)$ \\
$\bar{\lambda}_{H}$ & -0.0169 & $(0.0340)$
\end{tabular}

Table 1: Parameter estimates: This table reports our results from the estimation of the house price process based on $N=55$ annual observations with $\Delta t=1$ year using the regression $\log \left(\frac{H_{t+1}}{H_{t}}\right)=a+b \log \left(\frac{H_{t}}{H_{t-1}}\right)$. Due to the finite sample, standard errors where computed using Monte Carlo simulation. 


\begin{tabular}{lrr} 
Description & Parameter & Value \\
\hline Risk aversion & $\gamma$ & 10 \\
Housing preference & $\psi$ & 0.2 \\
Utility discount factor & $1 / \delta$ & 0.96 \\
Risk-free rate & $r$ & $\ln (1.02)$ \\
Stock price volatility & $\sigma_{s}$ & 0.16 \\
Risk premium stocks & $\lambda_{s}$ & 0.04 \\
Long-term average risk premium housing & $\lambda_{H}$ & -0.0169 \\
Instantaneous volatility house price & $\sigma_{H}$ & 0.1332 \\
Volatility predictive signal & $\sigma_{\xi}$ & 0.0405 \\
Mean-reversion house premium & $\kappa$ & 0.1478 \\
Unconditional average log-return house & $\bar{\xi}$ & 0.0022 \\
Correlation stock, house price & $\rho_{S H}$ & 0.22 \\
Correlation stock, signal & $\rho_{S \xi}$ & 0.22 \\
Correlation stock, labor & $\rho_{S L}$ & 0.2 \\
Correlation house price, signal & $\rho_{H \xi}$ & 0.9967 \\
Correlation house price, labor & $\rho_{H L}$ & 0.2 \\
Correlation signal, labor & $\rho_{\xi L}$ & 0.2 \\
Sensitivity signal & $\beta$ & 0.8567 \\
Minimum equity requirement for house purchase & $E^{\text {min }}$ & $20 \%$ \\
Renting costs rate & $m^{\text {rent }}$ & $7.0 \%$ \\
Maintenance costs rate & $m^{\text {own }}$ & $1.5 \%$ \\
Moving costs owner & $\nu_{\text {own }}$ & $8.0 \%$ \\
Moving costs renter & $\nu_{\text {rent }}$ & $1.0 \%$ \\
Replacement ratio & $R_{\text {retire }}$ & $70 \%$ \\
Volatility labor income process & $\sigma_{L}$ & $10 \%$ \\
\hline
\end{tabular}

Table 2: Parameter values: This table reports our choice of base case parameter values. 


\begin{tabular}{|c|c|c|c|c|c|c|c|c|c|c|}
\hline \multirow[b]{2}{*}{ Age } & & & \multicolumn{2}{|c|}{$\underline{B a s e}$ case } & \multicolumn{2}{|c|}{$\rho_{S H}=0.5$} & \multicolumn{2}{|c|}{$\rho_{H L}=0.5$} & \multicolumn{2}{|c|}{$\underline{\kappa=0.2922}$} \\
\hline & & & Owner & Renter & Owner & Renter & Owner & Renter & Owner & Renter \\
\hline \multirow{9}{*}{25} & \multirow{2}{*}{ Equity exposure } & Mean & 0.25 & 0.47 & 0.30 & 0.49 & 0.23 & 0.43 & 0.27 & 0.45 \\
\hline & & Std & 0.17 & 0.88 & 0.21 & 0.84 & 0.30 & 0.39 & 0.15 & 1.00 \\
\hline & \multirow{2}{*}{ Consumption } & Mean & 0.34 & 0.41 & 0.34 & 0.41 & 0.41 & 0.46 & 0.34 & 0.40 \\
\hline & & Std & 0.20 & 0.77 & 0.22 & 0.71 & 0.46 & 0.42 & 0.17 & 0.90 \\
\hline & \multirow{2}{*}{ Home size } & Mean & 1.05 & 1.32 & 1.01 & 1.31 & 1.10 & 1.49 & 1.00 & 1.27 \\
\hline & & Std & 0.59 & 2.49 & 0.62 & 2.26 & 1.24 & 1.36 & 0.48 & 2.85 \\
\hline & \multirow{2}{*}{ Bonds } & Mean & -0.68 & 0.02 & -0.69 & 0.00 & -0.78 & 0.00 & -0.64 & 0.06 \\
\hline & & Std & 0.40 & 0.06 & 0.44 & 0.00 & 0.89 & 0.01 & 0.33 & 0.14 \\
\hline & \multicolumn{2}{|l|}{ Ownership rate } & \multicolumn{2}{|c|}{0.78} & \multicolumn{2}{|c|}{0.74} & \multicolumn{2}{|c|}{0.44} & \multicolumn{2}{|c|}{0.83} \\
\hline \multirow{9}{*}{35} & & Mean & 0.21 & 0.44 & 0.25 & 0.70 & 0.26 & 0.49 & 0.22 & 0.40 \\
\hline & Equity exposure & Std & 0.12 & 0.98 & 0.18 & 1.39 & 0.21 & 0.68 & 0.09 & 1.23 \\
\hline & & Mean & 0.14 & 0.20 & 0.14 & 0.20 & 0.16 & 0.21 & 0.15 & 0.19 \\
\hline & Consumption & Std & 0.08 & 0.45 & 0.08 & 0.41 & 0.12 & 0.29 & 0.06 & 0.59 \\
\hline & & Mean & 0.58 & 0.63 & 0.56 & 0.64 & 0.58 & 0.68 & 0.54 & 0.60 \\
\hline & Home size & Std & 0.29 & 1.42 & 0.30 & 1.29 & 0.44 & 0.95 & 0.21 & 1.87 \\
\hline & & Mean & 0.05 & 0.32 & 0.03 & 0.05 & -0.02 & 0.25 & 0.08 & 0.37 \\
\hline & Bonds & Std & 0.13 & 0.71 & 0.16 & 0.15 & 0.15 & 0.35 & 0.13 & 1.14 \\
\hline & Ownership rate & & & & & & & & & \\
\hline & & Mean & 0.17 & 0.35 & 0.20 & 0.56 & 0.20 & 0.37 & 0.18 & 0.33 \\
\hline & Equity exposure & Std & 0.09 & 0.86 & 0.14 & 1.24 & 0.14 & 0.61 & 0.06 & 1.42 \\
\hline & Consumntion & Mean & 0.10 & 0.14 & 0.10 & 0.13 & 0.11 & 0.14 & 0.11 & 0.14 \\
\hline & Consumption & Std & 0.05 & 0.33 & 0.06 & 0.30 & 0.07 & 0.23 & 0.04 & 0.59 \\
\hline 45 & Home size & Mean & 0.44 & 0.42 & 0.42 & 0.43 & 0.45 & 0.44 & 0.41 & 0.43 \\
\hline & Home size & Std & 0.22 & 1.04 & 0.23 & 0.96 & 0.30 & 0.72 & 0.14 & 1.86 \\
\hline & & Mean & 0.27 & 0.48 & 0.26 & 0.27 & 0.23 & 0.46 & 0.29 & 0.50 \\
\hline & Bonds & Std & 0.15 & 1.18 & 0.16 & 0.62 & 0.18 & 0.76 & 0.11 & 2.20 \\
\hline & Ownership rate & & & & & & & & & \\
\hline & & Mean & 0.15 & 0.31 & 0.16 & 0.46 & 0.17 & 0.30 & 0.16 & 0.29 \\
\hline & Equity exposure & Std & 0.08 & 0.72 & 0.12 & 0.89 & 0.11 & 0.50 & 0.06 & 1.11 \\
\hline & & Mean & 0.10 & 0.12 & 0.10 & 0.12 & 0.10 & 0.12 & 0.10 & 0.12 \\
\hline & Consumption & Std & 0.05 & 0.29 & 0.06 & 0.24 & 0.07 & 0.20 & 0.04 & 0.46 \\
\hline 55 & Home size & Mean & 0.41 & 0.39 & 0.39 & 0.38 & 0.41 & 0.39 & 0.39 & 0.39 \\
\hline & Home size & Std & 0.22 & 0.92 & 0.24 & 0.75 & 0.28 & 0.64 & 0.15 & 1.49 \\
\hline & & Mean & 0.34 & 0.54 & 0.34 & 0.39 & 0.32 & 0.55 & 0.35 & 0.56 \\
\hline & Bonds & Std & 0.18 & 1.26 & 0.20 & 0.78 & 0.22 & 0.90 & 0.13 & 2.12 \\
\hline & Ownership rate & & & & & & & & & \\
\hline & & Mean & 0.24 & 0.36 & 0.27 & 0.48 & 0.24 & 0.37 & 0.25 & 0.33 \\
\hline & Equity exposure & Std & 0.14 & 0.75 & 0.22 & 0.64 & 0.14 & 0.70 & 0.11 & 0.93 \\
\hline & & Mean & 0.12 & 0.12 & 0.12 & 0.12 & 0.12 & 0.12 & 0.13 & 0.11 \\
\hline & Consumption & Std & 0.07 & 0.25 & 0.10 & 0.16 & 0.07 & 0.23 & 0.06 & 0.32 \\
\hline 65 & $\mathrm{Ho}_{\mathrm{O}}$ & Mean & 0.36 & 0.38 & 0.34 & 0.39 & 0.37 & 0.38 & 0.38 & 0.36 \\
\hline & size & Std & 0.20 & 0.81 & 0.27 & 0.53 & 0.22 & 0.73 & 0.16 & 1.04 \\
\hline & $\mathrm{B}_{\mathrm{C}} \mathrm{C}_{2}$ & Mean & 0.26 & 0.50 & 0.27 & 0.37 & 0.26 & 0.49 & 0.24 & 0.53 \\
\hline & as & Std & 0.20 & 1.04 & 0.26 & 0.52 & 0.20 & 0.93 & 0.17 & 1.50 \\
\hline & Ownership rate & & & & & & & & & \\
\hline & & Mean & 0.10 & 0.24 & 0.02 & 0.31 & 0.10 & 0.24 & 0.10 & 0.24 \\
\hline & Equity exposure & Std & 0.18 & 0.14 & 0.07 & 0.12 & 0.18 & 0.14 & 0.16 & 0.17 \\
\hline & & Mean & 0.29 & 0.27 & 0.30 & 0.26 & 0.28 & 0.27 & 0.29 & 0.27 \\
\hline & Consumption & Std & 0.51 & 0.17 & 0.92 & 0.11 & 0.50 & 0.16 & 0.44 & 0.19 \\
\hline 75 & Home size & Mean & 0.69 & 0.87 & 0.68 & 0.88 & 0.68 & 0.87 & 0.69 & 0.88 \\
\hline & Home size & Std & 1.24 & 0.56 & 2.07 & 0.39 & 1.22 & 0.55 & 1.05 & 0.64 \\
\hline & & Mean & -0.10 & 0.43 & -0.02 & 0.37 & -0.09 & 0.43 & -0.11 & 0.43 \\
\hline & Bonds & Std & 0.29 & 0.28 & 0.24 & 0.18 & 0.27 & 0.28 & 0.28 & 0.32 \\
\hline & Ownership rate & & & & & & & & & \\
\hline
\end{tabular}

Table 3: Comparative static analysis: This table depicts the average evolution of the consumption rate (Consumption), the equity exposure, the normalized home size (Home size), and the bond exposure for both owners and renters. All results are expressed as fractions of wealth before trading and consumption. The table further shows the probability that the household owns a home. Results are shown for our base case parameter setting (Base case), a setting where correlation between the stock and the house price process is set to $0.5\left(\rho_{S H}=0.5\right)$, a setting where the correlation between innovations in the house price and the labor income process is $0.5\left(\rho_{H L}=0.5\right)$, and a setting with shorter half-life for the housing market cycles $\left(\kappa=\mathbb{E}[\kappa]+\sigma_{\kappa}=0.2922\right)$. All results are based on 10,000 simulations on the respective optimal paths. 


\section{CFS Working Paper Series:}

\begin{tabular}{|c|c|c|}
\hline No. & Author(s) & Title \\
\hline $2010 / 20$ & $\begin{array}{l}\text { Mahmoud Botshekan } \\
\text { Roman Kraeussl } \\
\text { Andre Lucas }\end{array}$ & $\begin{array}{l}\text { Cash Flow and Discount Rate Risk in Up and } \\
\text { Down Markets: What Is Actually Priced? }\end{array}$ \\
\hline $2010 / 19$ & $\begin{array}{l}\text { Nikolaus Hautsch } \\
\text { Peter Malec } \\
\text { Melanie Schienle }\end{array}$ & $\begin{array}{l}\text { Capturing the Zero: A New Class of Zero- } \\
\text { Augmented Distributions and Multiplicative } \\
\text { Error Processes }\end{array}$ \\
\hline $2010 / 18$ & $\begin{array}{l}\text { Horst Entorf } \\
\text { Christian Knoll } \\
\text { Liliya Sattarova }\end{array}$ & $\begin{array}{l}\text { Measuring Confidence and Uncertainty during } \\
\text { the Financial Crisis: Evidence from the CFS } \\
\text { Survey }\end{array}$ \\
\hline $2010 / 17$ & $\begin{array}{l}\text { Nikolaus Hautsch } \\
\text { Mark Podolskij }\end{array}$ & $\begin{array}{l}\text { Pre-Averaging Based Estimation of Quadratic } \\
\text { Variation in the Presence of Noise and Jumps: } \\
\text { Theory, Implementation, and Empirical } \\
\text { Evidence }\end{array}$ \\
\hline $2010 / 16$ & Tullio Jappelli & $\begin{array}{l}\text { Economic Literacy: An International } \\
\text { Comparison }\end{array}$ \\
\hline $2010 / 15$ & $\begin{array}{l}\text { Bartholomäus Ende } \\
\text { Marco Lutat }\end{array}$ & $\begin{array}{l}\text { Trade-throughs in European Cross-traded } \\
\text { Equities After Transaction Costs - Empirical } \\
\text { Evidence for the EURO STOXX } 50-\end{array}$ \\
\hline $2010 / 14$ & $\begin{array}{l}\text { Terrence Hendershott } \\
\text { Albert J. Menkveld }\end{array}$ & Price Pressures \\
\hline $2010 / 13$ & Sarah Draus & $\begin{array}{l}\text { Does Inter-Market Competition Lead to Less } \\
\text { Regulation? }\end{array}$ \\
\hline $2010 / 12$ & $\begin{array}{l}\text { Kai-Oliver Maurer } \\
\text { Carsten Schäfer }\end{array}$ & Analysis of Binary Trading Patterns in Xetra \\
\hline $2010 / 11$ & $\begin{array}{l}\text { Annamaria Lusardi } \\
\text { Olivia S. Mitchell }\end{array}$ & $\begin{array}{l}\text { How Ordinary Consumers Make Complex } \\
\text { Economic Decisions: Financial Literacy and } \\
\text { Retirement Readiness }\end{array}$ \\
\hline
\end{tabular}

Copies of working papers can be downloaded at http://www.ifk-cfs.de 